Pringsheim, E. G. (1951). J. gen. Microbiol. 5, 124-149.

\title{
The Vitreoscillaceae: A Family of Colourless, Gliding, Filamentous Organisms
}

\author{
By E. G. PRINGSHEIM \\ Botany School, University of Cambridge
}

SUMMARY: A new family, the Vitreoscillaceae, is proposed for a group of microorganisms which are characterized by their colourless, gliding trichomes. The family has certain affinities with myxobacteria and still more with colourless myxophyceae, especially with the Beggiatoaceae.

Two genera, Vitreoscilla and Microscilla and seven species are described, three species tentatively referred to Vitreoscilla, two to Microscilla, and two other genera are provisionally named.

Colourless trichomes with a gliding movement are so common that it would be surprising if they had been overlooked, but descriptions are in many instances so vague that the species described cannot now be identified.

Cohn (1870-1, p. 121) mentions 'creeping, short, Oscillaria-like filaments, composed of up to eight cylindrical sections, which exhibited a peculiar slow, gliding movement', which probably belonged to the group with which this paper deals. Van Tieghem (1880, p. 177) observed colourless Myxophyceae, perhaps Spirulina. The organism described by Winogradsky $(1888$, p. 23) as Beggiatoa minima i.e. forms not more than $1 \mu$. in width, does not, according to Lauterborn $(1915$, p. 419), belong to the sulphur bacteria and may well have been a member of the group here described. The flexible organisms described by Dobell $(1908,1912)$ do not appear to be related, since the author ascribes flagella to them. Spirulina albida (Kolkwitz, 1909, p. 137) is the first gliding, filamentous, heterotrophic organism which can be identified, while in a number of forms assigned to the genus Oscillatoria by various authors, lack of chlorophyll is not established beyond doubt (Pringsheim, 1949, p. 62).

A few myxobacteria (Garnjobst, 1945; Nigrelli \& Hutner, 1945) may be mentioned here. While the majority are not filamentous, but rod-shaped, those myxobacteria which form longer trichomes composed of several cells, are definitely colourless, gliding and filamentous. Their affinity with the organisms here described has therefore to be discussed in this paper. For lack of information I am unable to establish the taxonomic position of Soriano's (1947) Flexibacter which may either belong to the Vitreoscillaceae or more probably to the Myxobacteria.

Achroonema spiroideum, described by Skuja (1948), may also be related to the Vitreoscillaceae, although it is assigned by the author to the Oscillospiraceae, Peshkoff (1940). Oscillospira is, however, a true bacterium with flagella, showing a very different organization from that of the family here described (Pringsheim, 1949, p. 74). This taxonomic discrepancy has also struck Brunel (1949) who found a form similar to Skuja's, to which he even gives the same name, although the latter is $0 \cdot 3-0 \cdot 5 \mu$. wide, and Brunel's $1-1 \cdot 5 \mu$. This difference is not negligible since there may be more than one such organism. Experience 
shows that the Vitreoscillaceae comprise a large group of related forms. Skuja's taxonomic proposals are evidently influenced by Peshkoff's rather confused ideas (cf. also Bergey's Manual, 1948, p. 1002), and not based on personal knowledge of Oscillospira and Caryophanon which in no way resemble gliding organisms like Vitreoscilla to which Achroonema possibly belongs.

In 1947 I read a paper on this subject to the Society for General Microbiology and gave a demonstration of six species of Vitreoscilla in pure culture, illustrated by drawings, photographs and microscopical preparations. To change the name to Achroonema would thus cause confusion, especially as cultures were given to various laboratories, and an article, including descriptions of species, was published in Bacteriological Reviews (Pringsheim, 1949, p. 70).

\section{The gliding movement}

The word gliding is preferable to creeping or crawling which both suggest the movements of certain vertebrates, with which the gliding of these lowly organisms has no resemblance. Gliding movement will be called in this paper a translocation along solid bodies or the interface between water and air, during which no wriggling, contraction or peristaltic alterations are visible, the change of shape being restricted to bending. Whereas Peranema, a colourless, zootrophic eugleninean, generally moves along the surface of the water, myxophyceae do not seem to be able to do so, except when they support one another (Engelmann, 1879), and this appears to be true also of the Vitreoscillaceae. The gliding movements are not always regular, but intermittent and hesitant, with frequent changes of direction, as in the unicellular Myxophyceae and Rhodophyceae, Myxobacteria and Vitreoscillaceae (Pringsheim, 1949). While the suggestion that this kind of movement is caused by wave-like contractions, which was first put forward by Engelmann (1879, p. 55), then by Schmid $(1918,1919)$, and supported by experiments and observations by Ullrich (1926, 1929), has been generally accepted for filamentous Myxophyceae and Beggiatoaceae, it cannot easily be applied to unicellular organisms, and is very doubtful in the case of Myxobacteria, hormogonia of Myxophyceae, and Vitreoscillaceae. There is not even a hypothesis to explain the gliding of these organisms (Pringsheim, 1949, p. 65), except those based on the formation of mucilage. This was studied by Hansgirg (1887) who found that particles added to a preparation were carried in a definite direction, a phenomenon more fully investigated by Correns (1897) and by Kolkwitz (1897), and recently by Niklitschek (1934). Fechner (1915) explained the movement of Oscillatoria by an anisotropic swelling of the mucilage in a direction oblique to the axis, a hypothesis not widely accepted. In unicellular forms and those with short trichomes, however, unequal secretion of mucilage at the two poles might well provide the clue in those instances where waves of contraction cannot be accepted as an explanation. A polar exudation of mucilage as a method of locomotion is known in many lowly organisms.

All the gliding structures which are appreciably longer than they are wide show a marked flexibility. Probably this does not mean active bending (Correns, 1897) but only a lack of rigidity, so that small obstacles to their 
progress may cause a distortion (Pringsheim, 1949, p. 65). This pliability is probably due to the absence of a cell wall, although in some cases it is the connecting link between the cells rather than the cells themselves which is least resistant to bending.

\section{THE VITREOSCILLACEAE}

The organisms described below bear so close a resemblance to certain members of the Oscillatoriaceae that they may be considered to be colourless Myxophyceae. This is borne out by the following features which they have in common with the latter: the lack of true nuclei, filamentous habit, gliding locomotion, reproduction by hormogonia. Some species might even be mistaken for faintly coloured species of Oscillatoria or sulphur-free Beggiatoa. Others differ in having short trichomes, but these are also found among true, pigmented Oscillatoriaceae.

The number of colourless, gliding, filamentous organisms seems to be considerable. Those described by Soriano (1947) differ from those I have found, and all those $I$ have isolated in pure culture represent distinct species. It will take time to describe the group more completely; at present only those which have been grown in bacteria-free culture, and a few readily recognizable forms, can properly be named.

Localities where members of the Vitreoscillaceae can usually be found are the following: floating masses of pigmented Myxophyceae, water with decaying plant material, mucilage formed by other organisms, water-flowers of Chroococcaceae, cow dung, and manured soil.

The members of the Vitreoscillaceae differ from one another mainly in the width of their trichomes, and in the ratio of the width to the length of their cells. Some have barrel-shaped cells, divided by constrictions, others a cylindrical shape of even width. They also vary in their degree of flexibility and in the celerity of their movements. The latter two characters determine the type of movement and the shape of the trichomes. The more rigid forms move mainly in a longitudinal direction with only their free ends rotating in a narrow angled cone, in a way similar to that of the wider species of Oscillatoria. The pliable species appear as curved, irregularly wavy threads which change continually in shape and direction of movement.

The more moniliform species have a marked tendency to break up into short, hormogonium-like lengths whereas the cylindrical ones grow out into filaments of almost unrestricted length, as also occurs in certain species of Oscillatoria and Beggiatoa.

Some species of Vitreoscillaceae might be regarded as unpigmented species of the genus Oscillatoria in the same way as Spirulina albida (Pringsheim, 1949, p. 62) is assigned to its genus despite its lack of pigmentation. Those which resemble Beggiatoa differ from that genus in their inability to form sulphur from hydrogen sulphide and may even occur among Beggiatoa trichomes, which are themselves full of sulphur, without containing any. In view of the number of species and the gradual transition between long filamentous forms and those which retain a hormogonium-like state, which is distinctly different from the 
general condition in Oscillatoria, the group was given a new name, the Vitreoscillaceae with Vitreoscilla beggiatoides n.sp. as the type. They could perhaps be included in Soriano's (1947) Flexibacteriales if this order were revised (Pringsheim, 1949, p. 85).

The Vitreoscillaceae are provisionally divided into four genera: Vitreoscilla, Microscilla, Bactoscilla and Flexoscilla. In Vitreoscilla the trichomes are composed of well-marked cells, cylindrical like those of Beggiatoa alba, or barrel-shaped like those of Beg. mirabilis. Microscilla possesses narrower filaments, in which cells cannot be discerned by optical means, although this difference may prove to be only one of size. Soriano's (1947) genus Flexibacter may possibly overlap with Microscilla, but my forms are definitely not bacteria. Bactoscilla is peculiar in that its trichomes are composed of rod-shaped sections connected by pliable links. Flexoscilla represents slender rods becoming narrower at each end. Pure cultures were obtained only of species of Vitreoscilla and of Microscilla.

\section{VITREOSCILLA n.gen.}

\section{Species grown in pure culture}

Vitreoscilla beggiatoides n.sp. This species was first isolated in 1941 from a ditch on Coldham Common, Cambridge, with decaying water weeds, where it occurred together with Sphaerotilus discophorus, Beggiatoa alba, and many bacteria. After plating in various ways had failed, floating trichomes were washed five times with the help of capillary pipettes and transferred singly to agar plates. In one Petri dish, with Heyden agar, after a week the entire surface was covered with colourless curling filaments, from which a new plate was inoculated by streaking. Transfers from this remained free from bacteria. The observation of isolated nests of development at a distance from the main growth confirmed the identity of the organism, which can glide over the agar. The ease with which bacteria-free cultures were obtained is due to this ability to glide.

The trichomes of this species are about $2 \mu$. wide, sometimes more or less, and may grow so long that they cannot be measured with certainty, being curved and more than $150 \mu$. in length. They often show shallow constrictions at distances of 4-5 $\mu$. or more apart, evidently preformed places of division. The smallest trichomes are rarely shorter than $10 \mu$. and composed of two sections. All are rounded at the tip (Fig. 1). When cultivated in liquid media the trichomes may grow out into perfectly cylindrical filaments of almost unrestricted length before they show periodical constrictions and break up into short lengths, a kind of ill-defined hormogonia. On agar such long filaments are not formed. While young, healthy, growing trichomes scarcely show any inner structures except the septa, older ones contain many refractive granules. By staining with Robinow's technique (i.e. HCl-hydrolysis and Giemsa), nuclear bodies, which also give the Feulgen reaction, can be demonstrated.

The organism resembles a sulphur-free Beggiatoa and, like it, is motile while in a healthy condition. Under a cover-slip it ceases gliding and can then scarcely be distinguished from a sheathless Sphaerotilus filament. In hanging 
drops the movement begins after a few minutes during which the trichomes fasten themselves to the glass. The movement is a slow but perceptible steady advance in the direction of the axis. Direction may be reversed without visible cause. When gliding trichomes are caught between particles, one end swings funnel-wise in the way known in Beggiatoa and Oscillatoria. Filaments of the

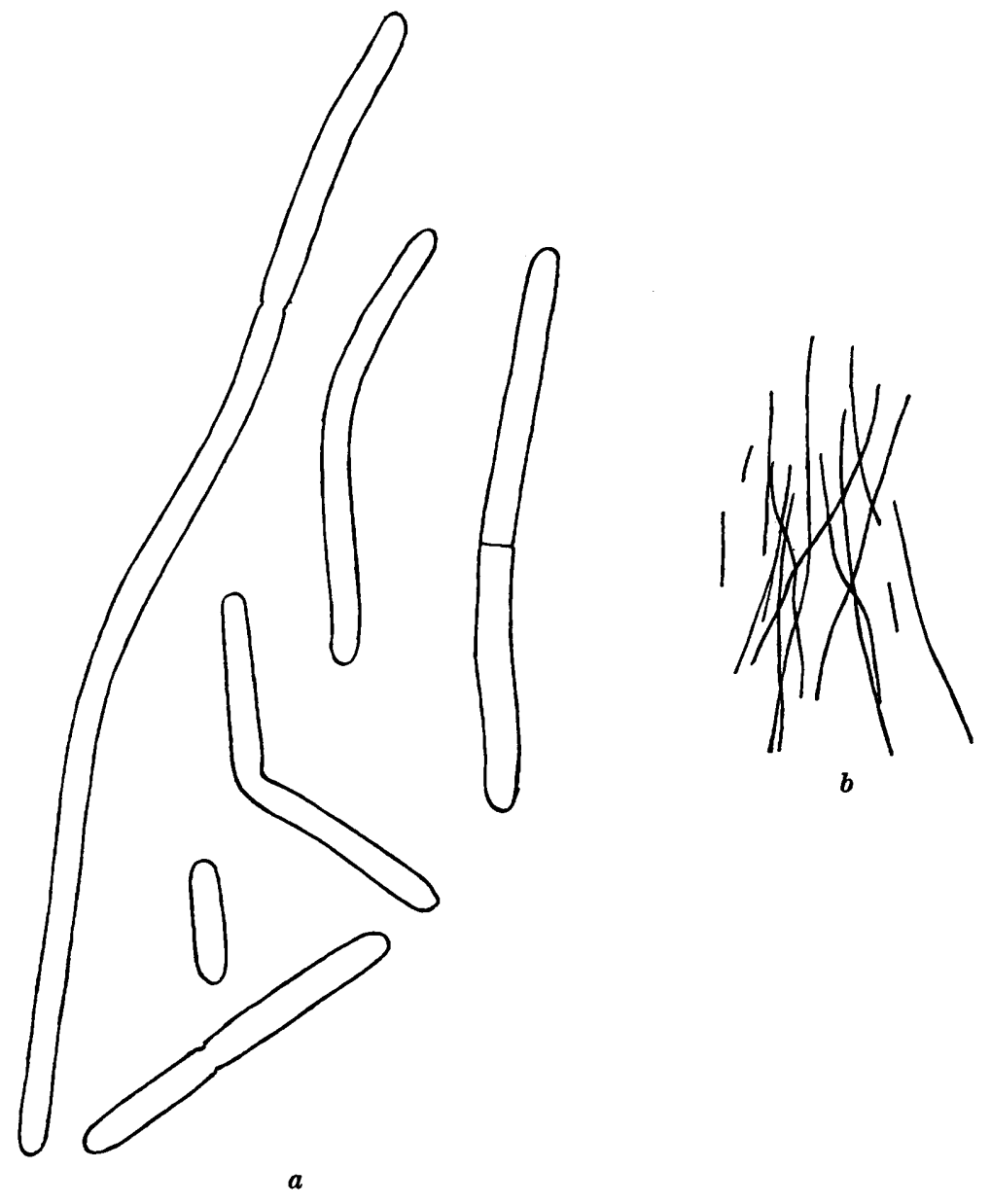

Fig. 1. Vitreoscilla beggiatoides. a. Trichomes of various lengths, all of them motile, $\times 1500$. $b$. Bundle of trichomes from liquid medium; $\times 200$.

same species do not seem to affect the movement in the same way as inanimate particles. The trichomes glide along each other, and on agar considerable numbers may arrange themselves in parallel. Bacteria and debris adhere to them very little; the reason is a soft mucilage of which no definite boundary can be demonstrated by indian ink.

The growth on agar is very characteristic; the trichomes form curls, spirals and waves (Figs. 2, 3). If the surface is not too dry they spread from the place of inoculation and colonize the whole area. In liquid media the cultures are 
not easy to see, owing to the low refraction of the organisms. Multiplication takes place most freely near the surface of the culture fluid adhering to the glass wall, whence small floccules can be seen to sink to the bottom at the slightest disturbance of the fluid. The best growth in a liquid occurs in the condensation water of agar slopes.

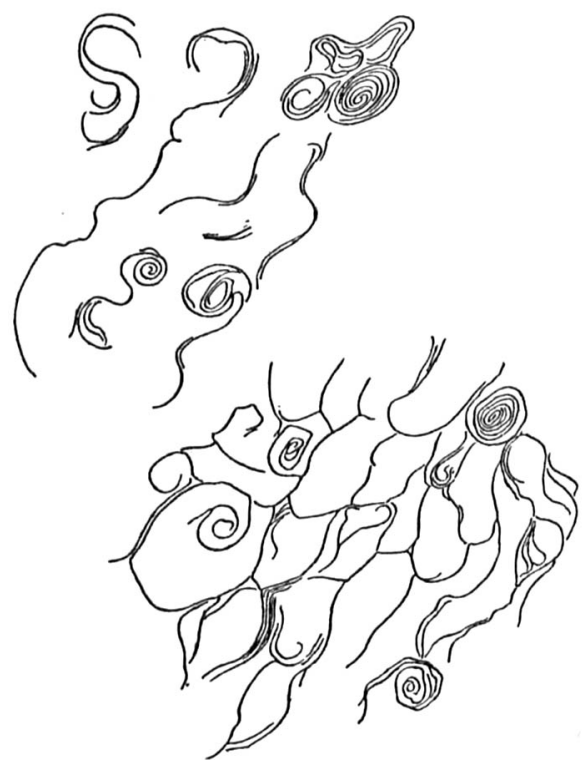

Fig. 2. Vitreoscilla beggiatoides. Dispersed growth with local spirals on agar with $0.2 \%$ Heyden nutrient + dilute Benecke solution; $\times 50$.

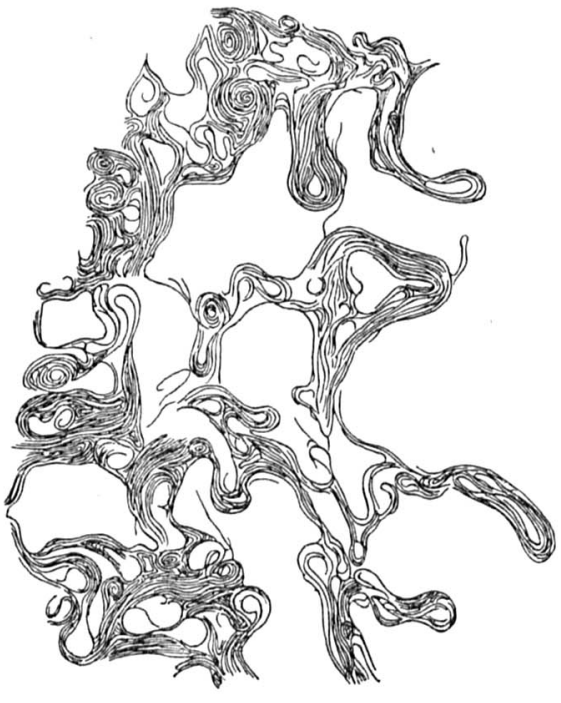

$a$

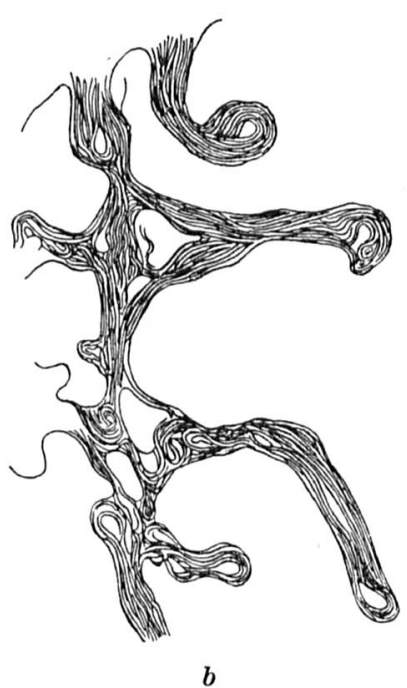

$b$

Fig. 3. Vitreoscilla beggiatoides. $a$. Edge of large colony on Heyden agar. $b$. Seven minutes later; note change in disposition of trichomes and projections; $\times 150$ (from photographs which, owing to the movement, were not sharp enough for reproduction).

G MV I 
Growth is abundant on agar media with beef-extract, yeast-extract, Difco proteose peptone (all $0 \cdot 1-0 \cdot 3 \%$ ) and still better in mixtures of them, if the concentration is not too high and the $\mathrm{pH}$ not lower than 6.5 . Glucose, acetate, glycerol and starch are without marked influence at low concentrations and harmful at higher ones. On a medium with 8-10\% gelatin growth is moderate, and the spreading, compared with agar, is restricted. Some growth may occur on plain gelatin which, however, is not liquefied, so that no proteolytic enzyme appears to be produced. This is confirmed by cultures upon casein agar which does not become translucent around the growth.

Vitreoscilla beggiatoides is found, but not regularly, in localities like the original habitat, i.e. quiet waters rich in organic matter, with black mud on the bottom, which often harbour a considerable variety of Vitreoscillaceae. Most of the trichomes are attached to solid bodies, but can be detached by shaking. The free-floating trichomes do not settle quickly and can be used for isolation.

Vitreoscilla catenula n.sp. This species was observed several times in ditches between meadows in Cambridge. Attempts at isolation, however, failed until apparently the same species was found in an infusion of cow-dung from the same meadow, and was streaked out on dung agar where it developed a similar growth to that of the former species. By repeated plating bacteria-free cultures were obtained, again by making use of its gliding motility for isolation.

Trichomes of this species may be cylindrical and of almost even width; usually there are constrictions between the cells, which are then barrel-shaped. They vary more in width than the previous species, being $1 \cdot 5-2 \mu$. in diameter and generally 3-4, sometimes up to $6 \mu$. long (Fig. $4 a-c$ ). The specimens first found in 1941 in material from a ditch in Cherry Hinton, Cambridge were of these dimensions, and so were those in the strain derived from cow-dung in 1945. For this reason these organisms are believed to be identical. No length of trichomes can be given; they may break up into short fragments or grow to some length.

Because of the constrictions between the cells, trichomes of $\boldsymbol{V}$. catenula resemble the blue-green genus $P$ seudanabaena, especially $\boldsymbol{P}$. tenuis Koppe, although there is no indication that they have originated from this slightly smaller form. The bead-like appearance of the cells is correlated with a greater tendency to break up into shorter lengths than is found in Vitreoscilla beggatoides. Very long filaments are rarely found in $V$. catenula. Another difference is the rounding off of the cells of the latter in old cultures, comparable to the 'involution' of bacteria and associated with a considerable increase of width.

In nutrition and the appearance of the growths upon agar and in liquid media, the two species are very similar.

Vitreoscilla filiformis n.sp. This species was first observed in November 1942 in a crude culture consisting of a grain of wheat covered with soil and water from the pond in the Cambridge Botanic Garden. The trichomes are more elastic than those of the other species, and on agar they form neatly rounded arches and loops like those of certain species of Oscillatoria (cf. Cataldi,1941, Pl. II, fig. B; Pl. III, fig. A) which are not found in any of the other Vitreoscilla cultures. This pronounced elasticity is combined with a greater tensilestrength 
so that very long filaments are formed, not only in liquid media but also on agar (Pl. 1, fig. 1). Shorter trichomes are, however, regularly present; both long

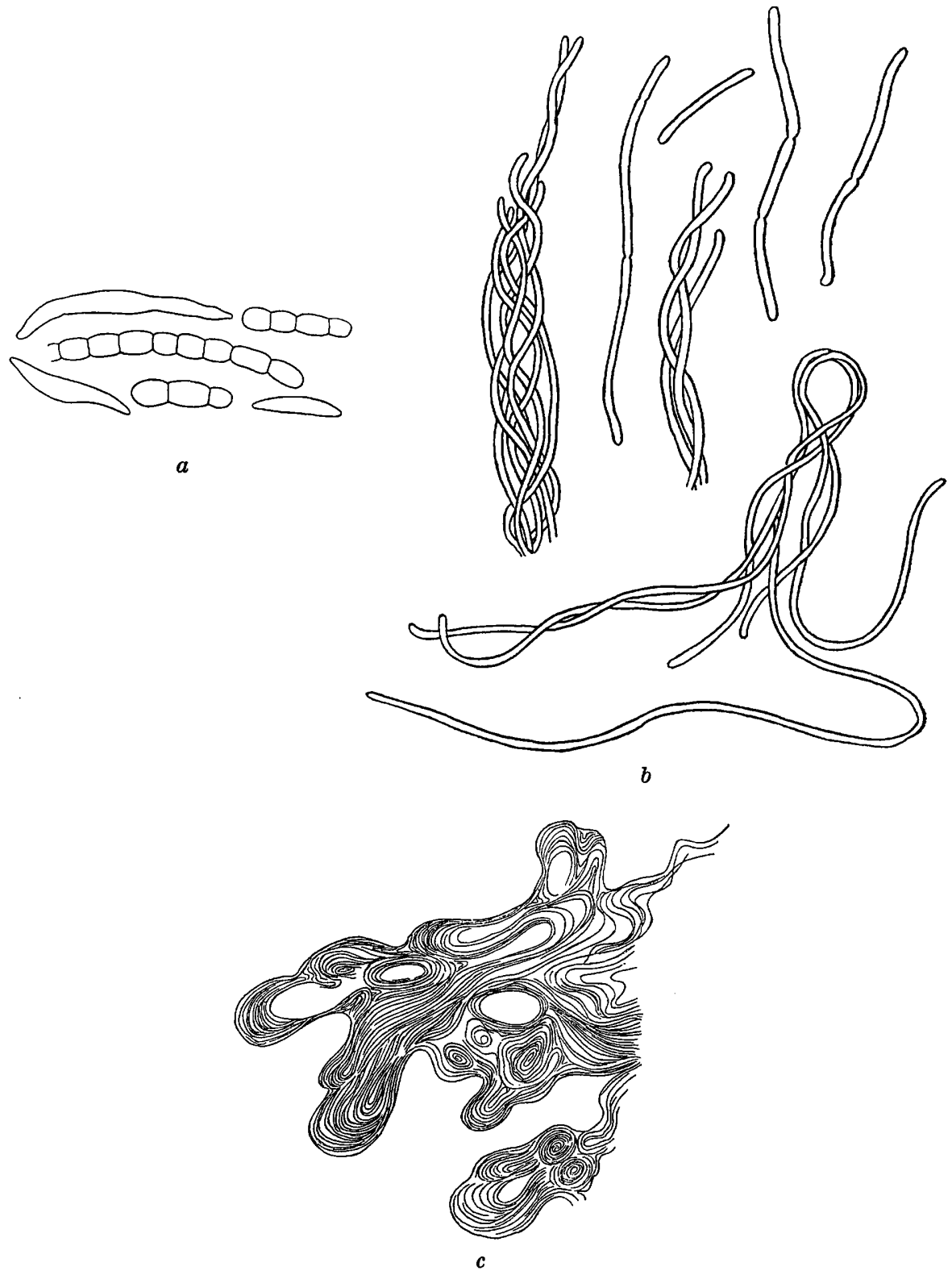

Fig. 4. Vitreoscilla catenula. a. Trichomes and involution forms, $\times 1500 . b$. Single trichomes and bundles; $\times 400$. c. Colony on yeast extract agar; $\times 100$.

and short ones exhibit an active gliding and swinging of free ends. The species is more slender than the two previously described, having a regular diameter of $1 \cdot 2 \mu$. 
From a non-nutrient agar plate, inoculated by Dr B. N. Singh with soil for studies on amoeba, the same or a very similar form was isolated by $\operatorname{Dr} \mathbf{R}$. Y. Stanier at Rothamsted Experimental Station (Pl. 1, fig. 2). Stanier used dung agar for the isolation which, however, was not suitable for maintenance so that the pure culture was lost, but I was given the opportunity of comparing it with my own cultures. This species was found again and grown in pure culture from cow manure streaked on $\mathbf{0} \cdot 1 \%$ proteose-agar. Maintenance was again difficult. No suitable medium was found other than the unreliable cow-dung agar which, because of its variable composition, makes subcultivation uncertain. This is also made difficult by the cohesion of the growth. Cultivation was possible on proteose and proteose beef-extract agar and on routine bacterial nutrient agar. $\mathbf{( 0 . 5} \%$ beef-extract $+\mathbf{0 . 5} \%$ Bactopeptone, $\mathrm{pH} \mathbf{7 \cdot 5})$. Higher concentrations and a slightly acid reaction prevented multiplication.

Apart from its smaller width $V$. filiformis differs from $V$. beggiatoides in the appearance of the colonies'on agar, which are delicate and almost circular, with a slightly denser centre and fringes at the periphery, while those of the latter are curly and have a very irregular outline. In liquid media $V$. filiformis develops initially only on the bottom, growing then higher up and outward from its points of attachment, whereas $V$. beggiatoides forms cobweb-like thin films, covering the inner surface of the tube, which later become denser and form loose agglomerations.

This species can easily be confused with Lineola longa Pringsheim (Pringsheim, 1950). This bacterium, likewise occurring in cow-dung, forms similar colonies and, under certain circumstances, very long filaments of nearly the same width. Differences are as follows:

Lineola longa

Flagellar movement

Constrictions preparatory to division

Cells very long

Easily breaks up into preformed rods

Colonies irregular, on suitable media thicker

In liquid media motile trichomes or silky bundles

Adheres to agar surface
Vitreoscilla filiformis

Gliding movement

Cylindrical of even width

Cells short

Tough threads; sometimes breaking up into short bits

Colonies rounded, delicate

Tassel formation on glass surface

Comes off readily as a whole

Vitreoscilla moniliformis n.sp. The organism was found by Dr C. F. Robinow in June 1947 on a plate of $0.3 \%$ yeast extract $+0.3 \%$ Bactopeptone agar inoculated with cow-dung. He noticed it to be peculiar in swarming periodically to form wider and wider circular zones on the agar surface, rather as Proteus does. He kindly gave me cultures for further investigation.

In order to obtain pure cultures plating was repeated, and various liquid and agar media were inoculated from isolated colonies by the use of capillary pipettes. At $22.5^{\circ}$ and $27^{\circ}$ growth was well developed after one day. On a routine bacteriological agar circular colonies with zonal growth were formed. On neutral $0.2 \%$ Difco yeast extract agar growth was similar but less profuse. In Bactopeptone + yeast extract and in Bactotryptone + yeast extract solu- 
tions, $\mathbf{0 . 3} \%$ in each case, a homogeneous turbidity developed which, under a strong hand-lens, was seen to be composed of trichomes. As with many bacteria and other saprophytic micro-organisms, mixtures of yeast extract or beef extract with various peptones support growth better than either one alone.

On plates the growth of Vitreoscilla moniliformis can be seen at low power to be composed of relatively large, streptococcus-like chains (Pl. 2, figs. 3, 4). The trichomes in mounted preparations were found to be up to $150 \mu$. in length but generally only $30 \mu$. long. They are composed of a limited number of rod-shaped sections which are rounded at their ends and often appear to be interrupted by short gaps (Fig. $5 a$ ), but the trichomes move as a whole. The sausage-shaped sections are mostly $2 \cdot 2-2 \cdot 5 \mu$. wide and not very regular in form, often inflated to a diameter of $2 \cdot 8-3 \cdot 0 \mu$., sometimes little longer than they are wide, but sometimes as long as $15 \mu$., elongated and cylindrical. They tend to separate from one another. Units of four to five cells are often found. The point where a cell divides is marked long before by a constriction.

The movement of this big Vitreoscilla is never very active, as there is in the Vitreoscillaceae an inverse ratio between width and speed of movement. Only in young cultures is the movement directly perceptible under the microscope. If cultures are kept at $26^{\circ}$ motility is most pronounced after $4-6 \mathrm{hr}$. and even then, observed in a hanging drop it is irregular and interrupted. The movement often appears as a flexion between two stiff rod-shaped cells, but even single cells, with only an indication of constriction near the middle, may be motile, so that the source of movement cannot lie in the joints between the cells. These are merely the points of least resistance, and bending seems to be due to friction (cf. Pringsheim, 1949, p. 84).

No cell-walls could be detected by normal illumination in spite of the relatively large size of the cells. By dark-ground illumination the edges of the cells are brightly illuminated, so that there is evidently a denser layer, which can also be demonstrated by staining (Pl. 2, fig. 4). By the use of hypertonic solutions, e.g. $5 \%$ glucose or double concentrated sea water, irregular shrinking is caused without cell-walls becoming visible, so that one cannot speak of plasmolysis (cf., for example Lineola Pringsheim, 1950). The growth on agar is not always very characteristic and may be rather diffuse, but the edges, particularly on less rich media, are composed of tongue-like processes while rounded, twisted areas may be seen in the interior of large colonies (Fig. 5b,c). Against the light the growths are yellowish, against a dark background they show a mother-ofpearl effect. In liquid media, a marked turbidity and later a sediment, is formed. On the whole Vitreoscilla moniliformis grows more rapidly and abundantly than the other species, and is not fastidious in its food requirements but does not produce proteolytic enzymes (gelatin; casein-agar tests).

Vitreoscilla paludosa n.sp. The species was detected in November 1947 in material from the mill-pond above Flatford Mill Field Centre after it had been kept in the laboratory for a month. It had previously contained Diatoms and Myxophyceae, Trachelomonas, Phacus, Pandorina. Plates were inoculated in two ways : at separate points, and by streaking. After 1 day, threads and tongues composed of many trichomes had grown out on $0.1 \%$ beef extract and on $0.2 \%$ 
yeast extract agar. On one of the streaked plates isolated colonies had developed, from which slopes were inoculated with a capillary pipette, and thus pure cultures were obtained.

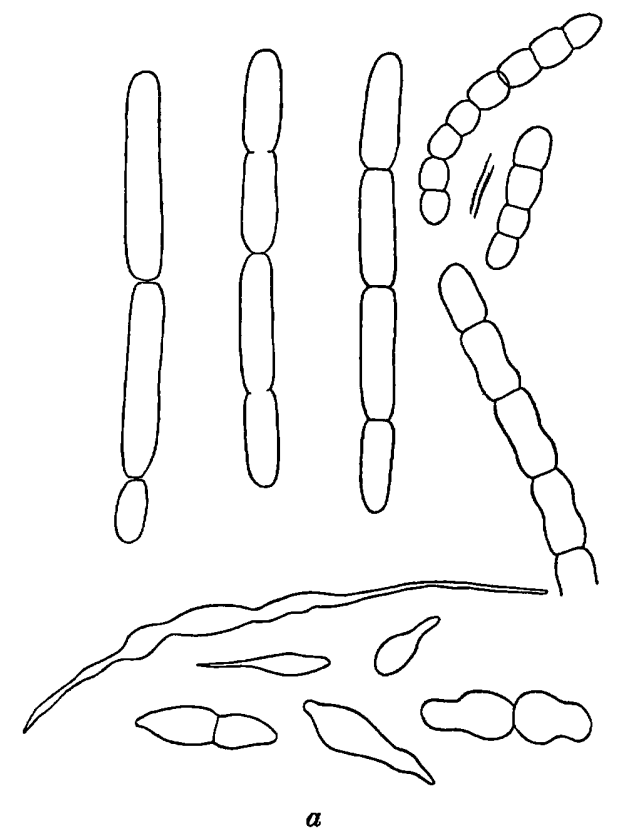

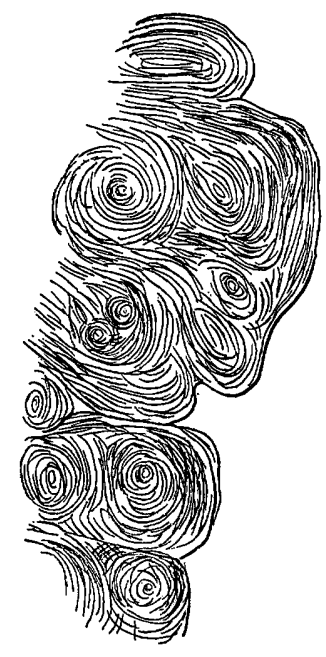

$b$

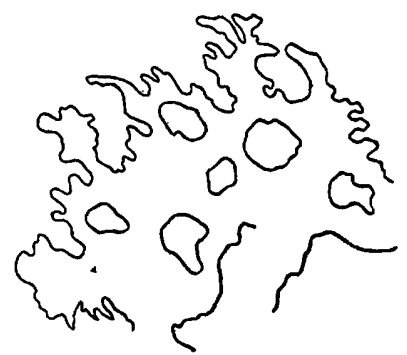

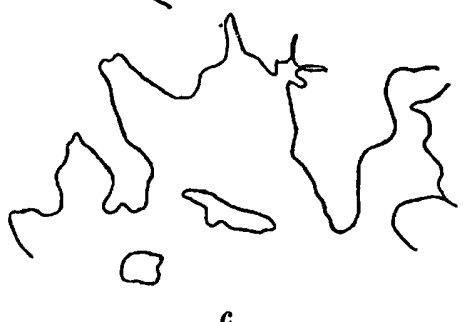

Fig. 5. Vitreoscillà moniliformis. a. Trichomes and involution forms; $\times 1500$. b. Colony on yeast extract agar, 10 days old; $\times 100$. c. Outlines of colonies on $0.2 \%$ yeast extract and $0.1 \%$ beef extract agar respectively; $\times 150$.

The appearance of the growths in liquid media and on agar recalls that of Beggiatoa which can be grown and isolated in the same way (Cataldi, 1940). On thinly inoculated agar young aggregations develop which are composed of 
parallel trichomes (Fig. $6 a$ ), and grow to form elongate, slender, pointed, often Y-shaped colonies (Fig. 6 b). Broadening occurs by the trichomes snapping on reaching a certain length, and the fragments slipping along one another; branching of colonies originates by one of the trichomes being thrust aside by the resistance of friction, and starting a new bundle. Older colonies have an inner concentric structure reminiscent of brain convolutions. At the edges

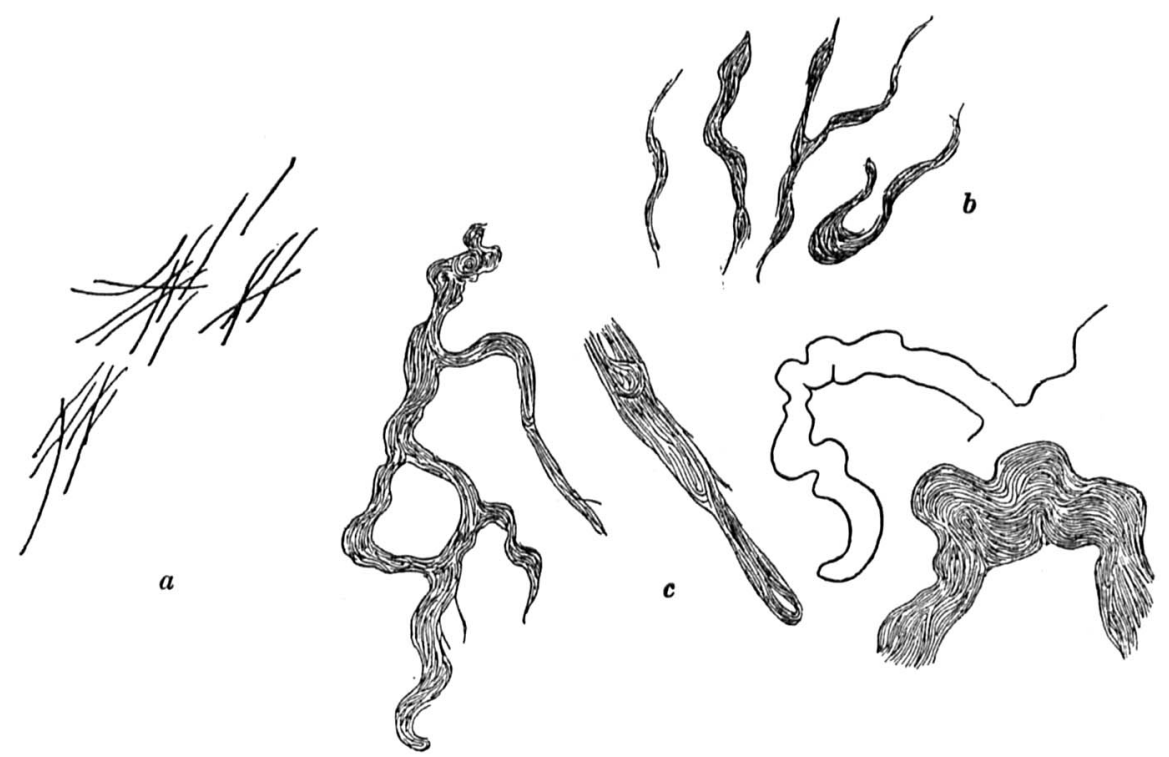

Fig. 6. Vitreoscilla paludosa. a. Bundles of straight trichomes; $\times 150 . b$. Younger, and, $c$, older colonies; $\times 150$; details $\times 300$.

they show flame-like processes and grow out into long curved and anastomosing tongues, from which again single trichomes emerge, commencing further systems of growth (Fig. 6c). The colonies are different from those of Beggiatoa in not producing curls and spirals at their fringes. In liquid media the trichomes may cover the glass surface with a film, or form cotton-like floccules, and eventually produce a sediment on the bottom.

The trichomes are $1 \cdot 8-2 \mu$. wide and may become very long, $300 \mu$. and more in length. They subdivide into cylindrical, often slightly curved cellular sections, 30-70 $\mu$. in length, separated by deep constrictions (Fig. 7a). At these places they could be observed to break during movement after bending at various angles. In one of the cultures grown in $0.1 \%$ beef extract medium definite branching was observed (Fig. $7 b$ ). Old cells contain spherical granules or droplets. The cell structure is the same as that of Vitreoscilla moniliformis. In an attempt to stain them negatively, with nigrosin + formalin, the cells collapsed and flattened in drying, often at right angles in neighbouring cells. If, however, they were first dried and then covered with nigrosin their 
appearance was better preserved, outlines and constrictions becoming clearly visible.

The movement of $V$. paludosa grown in liquid media may be very lively. In yeast extract $\mathbf{0 . 2} \%+$ Bactotryptone $0 \cdot 2 \%+$ soil extract the trichomes were extremely active in hanging drops, after attaching themselves to the surface (Fig. 8). Like all the other species under a cover-slip they ceased moving after a short time. $V$. paludosa is not exacting in its food requirements, although it

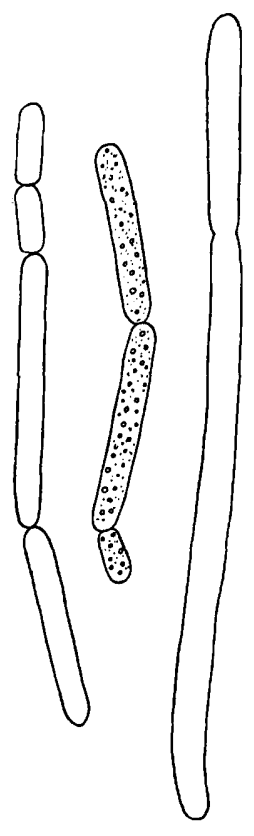

$\boldsymbol{a}$
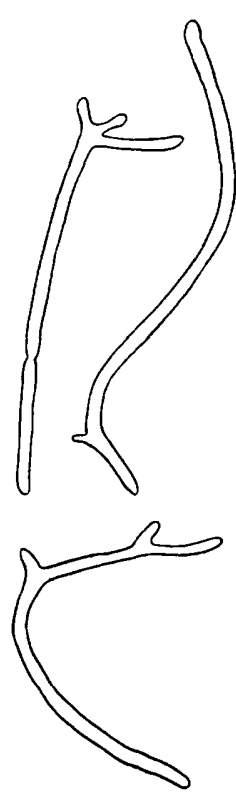

$\boldsymbol{b}$

Fig. 7. Vitreoscilla paludosa. a. Trichomes, one of them showing granules; $\times 1500$. b. Branching as an anomaly; $\times 600$.

does not produce proteolytic enzymes. On bacteriological agar it grows so luxuriantly that it can scarcely be distinguished from Escherichia coli, while on $\mathbf{0 . 1} \%$ beef extract agar its growth is poorer but conspicuous by its filamentous structure. It also grows well and rapidly in liquid media.

The species does not seem to be rare. Similar trichomes were repeatedly seen among the debris of raw cultures.

Vitreoscilla stercoraria n.sp. This species was isolated from dung; hence the name. In trying to isolate Caryophanon from cow droppings (Pringsheim \& Robinow, 1947) in May 1946, particles of dung were seeded on Difco nutrient agar with $\mathbf{0 . 2} \%$ yeast extract. After two days streptococcus-like chains had spread out upon the surface of the agar; these soon formed beautiful curls and vortices. It was easy to transfer pure material to new plates with a capillary pipette and from these to agar slopes in order to obtain bacteria-free cultures.

The trichomes of this species are about $1 \cdot 2-1 \cdot 5 \mu$. across and of varying length 
up to $100 \mu$. Their appearance is inconstant, they may be composed of rods of considerable length, $12 \mu$. and more, or of cells which are not much longer than they are wide (Fig. $9 a$ ). The terminal cells show no more peculiarity than in the other species of the genus; the cell structure is also the same. If above a

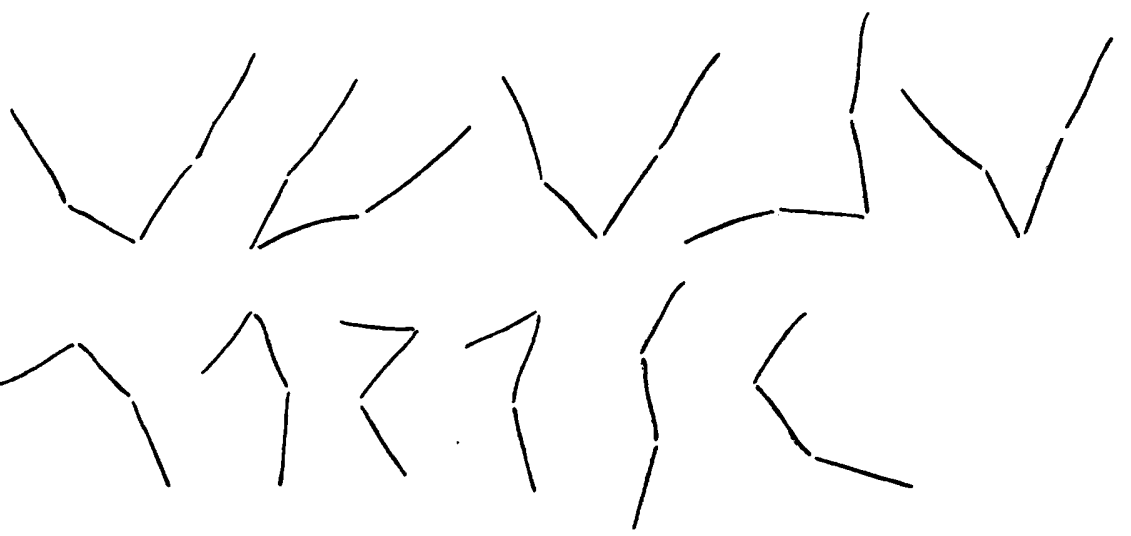

Fig. 8. Vitreoscilla paludosa. Changing appearances of two trichomes; $\times 135$.
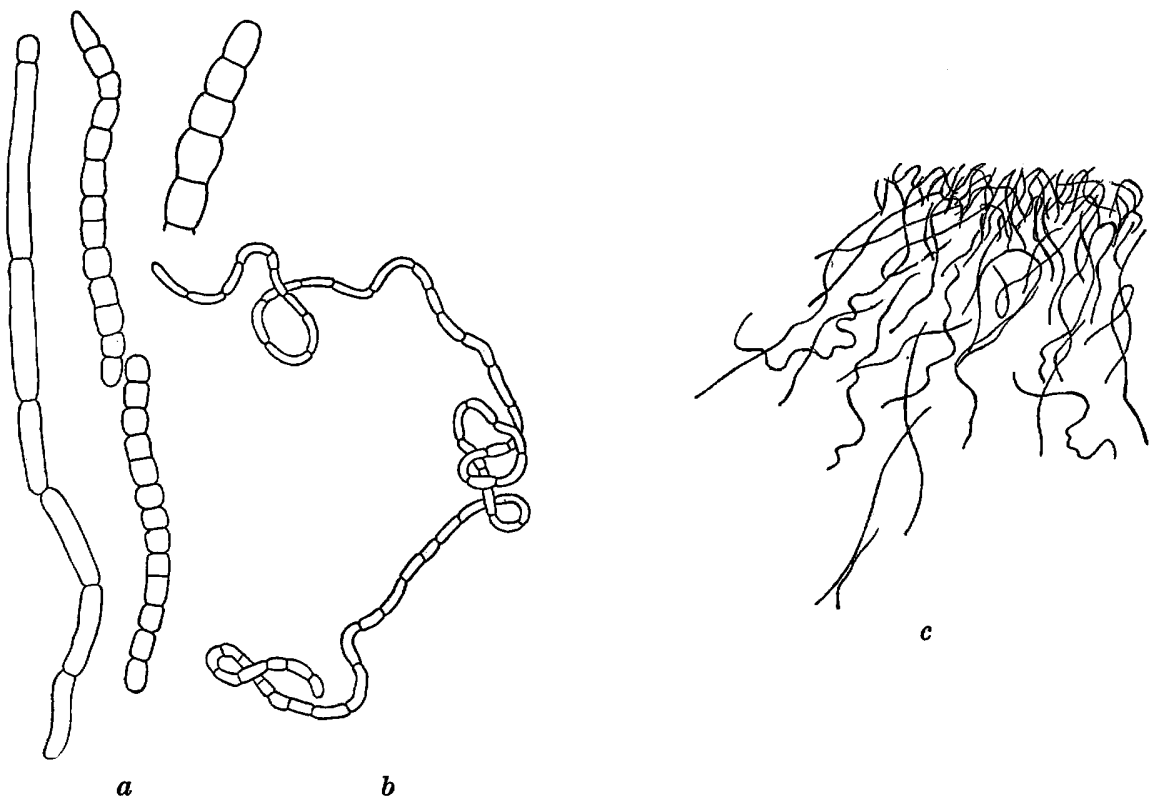

Fig. 9. Vitreoscilla stercoraria. $a$. Trichomes of various appearances; $\times 1250$. b. Long, irregularly bent trichome, characteristic of the species; $\times 700 . \quad c$. Edge of a floccule, giving the same wavy and looped appearance; $\times 100$.

certain length the trichomes rarely remain straight but bend irregularly forming aggregates like curled hair (Fig. $9 b, c)$. The movement is hesitant and slow.

$V$. stercoraria grows more abundantly than $V$. catenula which it rather 
resembles, although it is somewhat wider and more liable to produce irregular cells. It also forms on agar denser colonies connected by a fine network, a very characteristic feature. The formation of almost regular spirals is again similar to that of $V$. catenula, but the colonies become thicker on a rich medium and, after some time, grow yellowish and translucent, owing to autolysis of the cells. The filamentous appearance is, as usual, more noticeable on low concentrations of nutrients, e.g. $\mathbf{0 . 0 5} \%$ yeast extract and $0 \cdot 1 \%$ beef extract agar. On higher concentrations of yeast extract, up to $0.5 \%$, particularly when supplemented with peptone and on bacterial nutrient agar, the growth becomes very abundant. In liquid media the growth is at first filamentous and loose but later becomes more flocculent. The variability of appearance is considerable (Fig. 9).

Species of Vitreoscilla isolated in pure culture

\begin{tabular}{|c|c|c|c|}
\hline Name of species & Width $(\mu)$. & Morphological features & Culture appearance \\
\hline$V$. beggiatoides & $1 \cdot 2$ & $\begin{array}{l}\text { Straight trichomes; cells } \\
\text { longer than wide }\end{array}$ & Curls and tongues \\
\hline V. catenula & $1 \cdot 2$ & $\begin{array}{l}\text { Moniliform; fragments } \\
\text { readily }\end{array}$ & Curls and spirals \\
\hline$V$. filiformis & $1 \cdot 2$ & $\begin{array}{l}\text { Long, tough trichomes; } \\
\text { cells longer than wide }\end{array}$ & $\begin{array}{l}\text { Circular twirls and long } \\
\text { loops }\end{array}$ \\
\hline $\boldsymbol{V} \cdot$ moniliformis & $\mathbf{2 \cdot 3}$ & $\begin{array}{l}\text { Straight trichomes with } \\
\text { short or elongate cylin- } \\
\text { drical cells }\end{array}$ & $\begin{array}{l}\text { Diffuse growth or locks } \\
\text { and tongues }\end{array}$ \\
\hline$V \cdot$ paludosa & $1 \cdot 8-2$ & $\begin{array}{l}\text { Straight trichomes with } \\
\text { long cells }\end{array}$ & $\begin{array}{l}\text { Colonies with concentric } \\
\text { structure, no curls }\end{array}$ \\
\hline$V$. stercoraria & $1 \cdot 2-1 \cdot 5$ & $\begin{array}{l}\text { Trichomes often irregu- } \\
\text { larly bent, moniliform } \\
\text { or composed of sausage- } \\
\text { shaped cells }\end{array}$ & $\begin{array}{l}\text { Colonies spiral, connected } \\
\text { by fine threads }\end{array}$ \\
\hline
\end{tabular}

Species not grown in pure culture

The following organisms could not be grown in pure culture and are included in the genus only with reservations.

Vitreoscilla major, nom.prov. A test-tube containing starch, soil and water was inoculated in September 1940 with half-dried mud from a ditch at Cherry Hinton, Cambridge, and kept in the dark at $25^{\circ}$. Two months later, following a profuse development of various Astasiaceae, a very peculiar growth appeared, consisting of tufts radiating from a point on the surface of the mud and composed of relatively long, colourless trichomes, 6-7 $\mu$. wide (Fig. 10a,b). The appearance recalled that of Thiothrix from which, however, the organism differed by its continuous active bending and twisting.

The trichomes were composed of cells, their length slightly less than their width, on the average $5 \mu$. long, with a few refractive granules near the septa, as found in certain species of Oscillatoria. The terminal cells were in the form of flattened hemispheres (Fig. 10b). Seen from the tip, the trichomes rotated clock-wise. Particles adhering to the surface generally moved towards the middle of the trichomes where they accumulated in the same way as in 
Oscillatoria and Beggiatoa. The organism was completely colourless and, as it had developed in the dark, it cannot have been photosynthetic. Its appearance was different from any known member of the Beggiatoaceae.
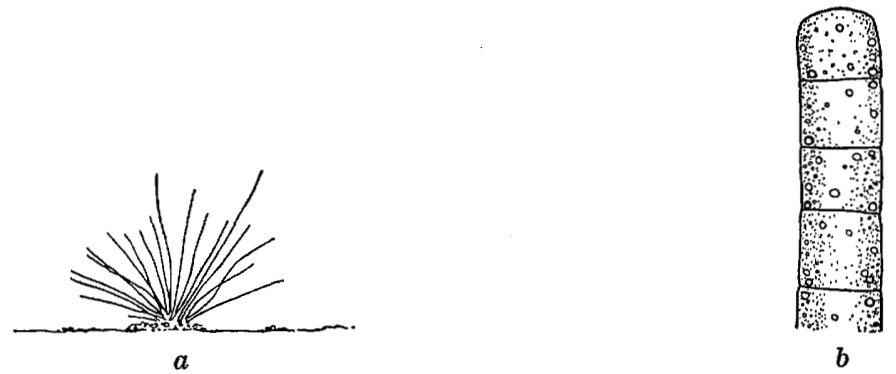

Fig. 10. Vitreoscilla major. a. Tuft; $\times 150 . \quad b$. End of trichome; $\times 1250$.

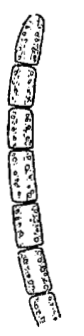

$a$

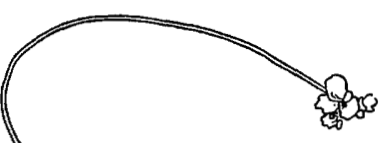

Fig. 11. Vitreoscilla stricta. $a$. End of trichome; $\times 1250 . \quad b$. Trichome caught at both ends between debris particles; $\times 300$.

Fig. 12. Vitreoscilla conica. End of trichome; $\times 1250$.

Vitreoscilla stricta nom.prov. This organism, which was found at Wray Castle and at Flatford Mill, has a diameter of $1 \cdot 6-1 \cdot 8 \mu$. and forms relatively short trichomes of up to $30 \mu$. which bend slowly and only to a small extent. True locomotion has not been observed (Fig. 11 $a$ ). The sluggishness of the trichomes seems to be correlated with their relative stiffness. They generally adhere to the detritus with one end while the other oscillates slowly. When both ends of a trichome were caught between particles it formed a bow and gradually freed itself by stretching before swinging in the ordinary way (Fig. $11 b$ ). The cells are clearly seen. They are on the average one and a half times as long as they are wide. The terminal cell is not very different from the rest but is rounded at the tip.

Vitreoscilla conica nom.prov. was found in mud from South Africa, very obligingly sent to our laboratory by Dr M. A. Pocock for the growth of Volvox and Hydrodictyon. It had been collected from a pond (Du Klip Vlei, Cape Flates, Cape Province) which had dried out during the dry season and was again moistened in the laboratory.

The trichomes of Vitreoscilla conica are about $4 \mu$. wide and never very long, generally 20-50 $\mu$. in length (Fig. 12). The cells are slightly barrel-shaped and filled with refractive pseudo-vacuoles. The end cell is often longer than the 
rest and attenuated towards the tip, hence the suggested specific name. The gliding movement was not active but, since its speed generally depends on temperature, this observation does not necessarily mean that the organism is equally sluggish in its natural habitat.

\section{MICROSCILLA n.gen.}

Since only one of the forms included in this genus could be grown in pure culture, the names should be considered as provisional. Most of the species were observed repeatedly but their identities could not be finally established owing to their relative lack of recognizable characteristics. The relation to Soriano's Flexibacter remains doubtful.

Microscilla marina n.sp. This organism appeared in November 1947 on plates of sea-water Schreiber agar inoculated with fragments of Schizonema (Diatom) filaments from Brighton. Colourless trichomes grew out upon the exposed areas of the agar surface and eventually could be freed from other organisms including bacteria. The organisms multiplied better when $0.05 \%$ Difco yeast extract or beef extract or various peptones were added, but not in higher concentrations than $\mathbf{0 . 2} \%$. Glucose did not have an enhancing effect; acetate supported slightly richer growth. Without sea-water there was no development at all. Sea water diluted $50 \%$ was, as in several other instances, slightly better than at full concentration. Sea water at double and one-quarter concentration permitted slight growth. Artificial sea water, although only approximately the natural composition, was quite as good as natural sea water. These observations, and those on Beggiatoa, on Porphyridium, on Myxophyceae and on various other algae and flagellates are not in accordance with van Niel's (1931, p. 31) view that there is no ecological-physiological difference between fresh-water and marine micro-organisms. This view had already been expressed by Baas-Becking (1925) and was repeated by ZoBell (1946).

Growth on agar slopes is not very conspicuous. On plain sea-water agar with dilute Benecke solution it may be almost invisible to the naked eye. The richest growth was obtained on the following medium: sodium acetate $0 \cdot 1 \%$, Difco yeast-extract $0 \cdot 1 \%$, Bactotryptone $0 \cdot 1 \%$, soil-extract $5 \%$, artificial sea water half concentrated, agar $1 \%$, neutralized with calcium carbonate. After 4 days a thick layer, peach to orange in colour, was formed. In other media this was only seen at the bottom of slopes where the organism had accumulated. The rich orange growth disappeared during the next week by autolysis of the cells, while smaller growths kept their filamentous appearance for several weeks.

The appearance of the organism could be observed more in detail when grown on agar plates (Fig. 13a-c). With the naked eye only a greyish veil can be seen which, under the microscope, is transformed into a delicate network of widely separated trichomes forming loops and meshes. At the edge of the area of growth there appear fringes and tongues composed of filaments, and single trichomes, occasionally wound together spiral-fashion. Very characteristic is the formation of denser aggregations in the otherwise very loose network (Fig. 13d).

The individual trichomes are $0 \cdot 5-0 \cdot 6 \mu$. wide, up to $100 \mu$. long and apparently 
without segmentation (Fig. 14a). The active gliding movement is not associated with rotation but with much bending and waving. Only when gliding along
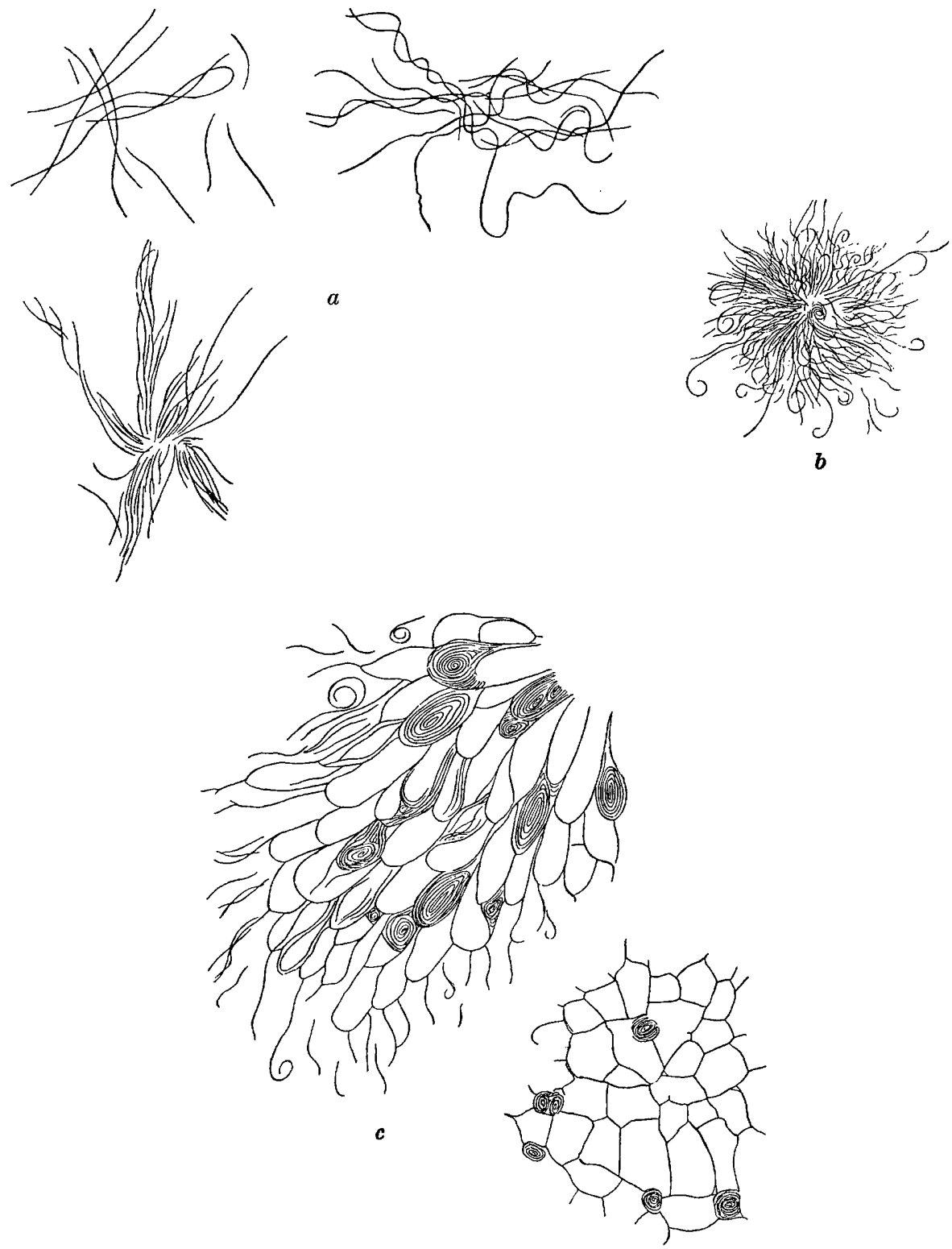

$d$

Fig. 13. Microscilla marina. $a$. Young colonies on agar, $\times 250$. b. Older colony, $\times 150$. c. Edge of old colony, yeast extract sea-water agar, $\times 75 . d$. Sparse growth on seawater agar with dilute Benecke solution without addition of organic substances, $\times 150$.

a glass surface may the trichomes become almost straight with slight, serpentine undulations. The movement is so quick, particularly in young material from 
liquid media, that it was only just possible to sketch the ever-changing shape of active trichomes. In the condensation fluid of agar slopes and in liquid media floating bundles of almost parallel trichomes are formed which continually glide along one another turning and twisting in various directions (Fig. 14b). When accidentally bent, they recovered their shape with great rapidity, but no free swinging ends were ever observed. The organism is delicate and had to be subcultured every week; it was lost during the hot summer of 1949. Since no effort was made to obtain the same or other marine members of the group it remains to be seen whether these can regularly be found.

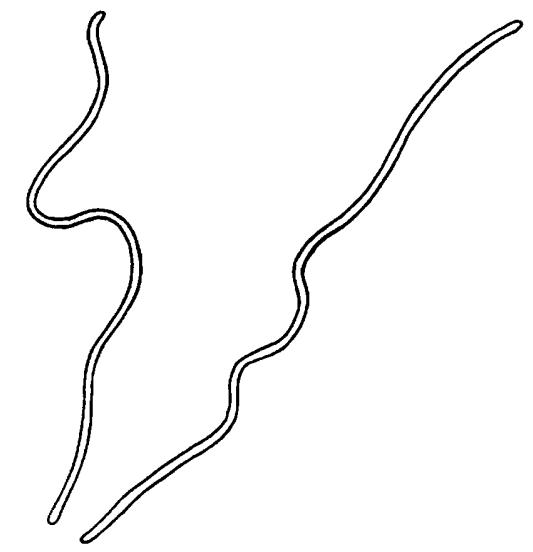

$\boldsymbol{a}$
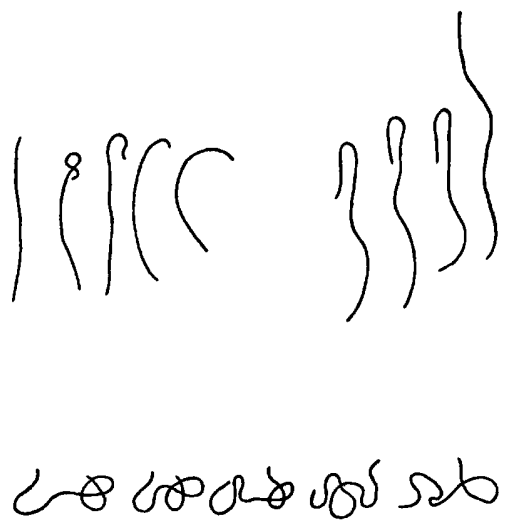

$b$

Fig. 14. Microscilla marina. a. Trichomes; $\times$ 1250. $b$. Three trichomes, consecutive stages of movement, quick sketches of changes in shape, liquid medium: proteose-peptone $0 \cdot 1 \%$ + beef-extract $0 \cdot 1 \%$ + soil-extract + sea water; $\times \mathbf{2 5 0}$.

Microscilla agilis nom.prov. This organism, which was at first mistaken for a spirochaete, was found in a ditch on Coldham Common near Cambridge in August 1941. The specimen contained, between decaying plant residues, a great variety of flagellates, Cladophora and Chlorohydra. The colourless trichomes of this Microscilla were $12-70 \mu$. long and $0 \cdot 6-0 \cdot 8 \mu$. wide, i.e. slightly wider than those of the previous species. No segmentation could be seen either in unstained preparations or those stained by neutral red, either by direct or dark-ground illumination. The coils of spirochaetes in the same field could clearly be seen, although these were narrower than the trichomes of $M$. agilis. The motility and flexibility of the organism were extraordinary and were reminiscent of Spirochaeta plicabilis (Fig. 15a). Moving on the cover-slip the trichomes were almost straight, but sometimes produced regular undulations. They glided along particles which they touched, continually changing their shape. On reaching the end the trichomes reversed the direction of their movement (Fig. 15b). The trichomes seemed always to be attached along their entire length; free, funnel-wise swinging ends were not seen. Rotation seems to be lacking. Except for its fresh-water habitat, the species is very similar to Microscilla marina. 
Microscilla flagellum nom.prov. This form is similar to the two just described but even more active and slender, attaining a width of barely $\mathbf{0 . 4} \mu$. Its long trichomes are common between pigmented filamentous Myxophyceae and can almost regularly be found in their floating masses on quiet waters, often with wider, more sluggish, perhaps not always completely pigment-free and more scattered trichomes. M. flagellum is also found between plant debris.

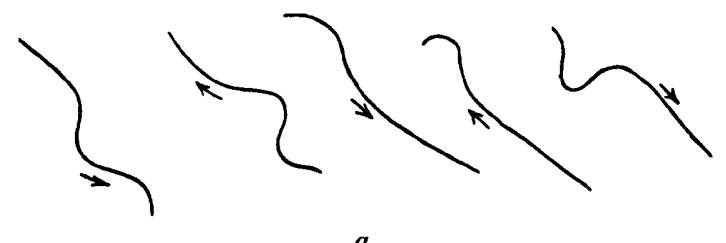

$\boldsymbol{a}$
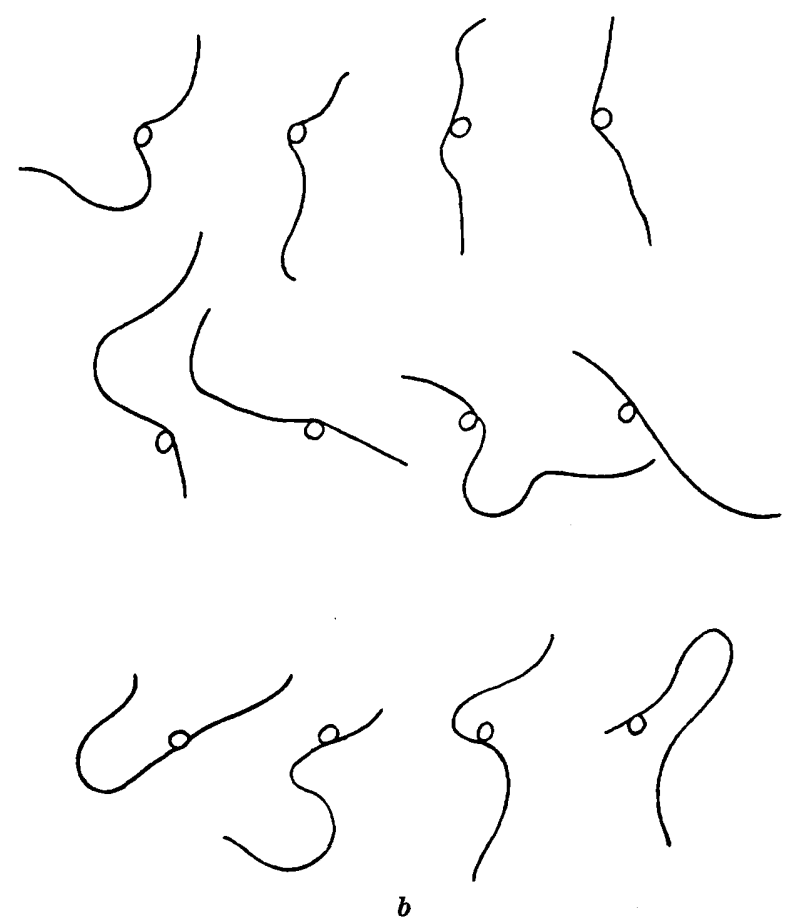

Fig. 15. Microscilla agilis. $a$. Sketches of quick changes in shape and in direction (indicated by arrow), exhibited by trichomes attached to cover-slip; $\times 500$. b. Similar; trichome glides along particle to which it remains attached in spite of translocation; $\times 500$.

In its usual habitat it is found in great numbers, gliding, and twisting among the much larger trichomes of Oscillatoria, Phormidium and Anabaena sometimes winding in a spiral around them. The extremely active movements of trichomes fixed at one end recall to some extent those of flagella of euglenoid flagellates trapped between particles of debris, hence the specific name. When gliding the trichomes continually change their shape and direction. They may lash about like a whip or turn back upon themselves to form hooks and loops. 


\section{BACTOSCILLA nom.prov.}

Only one species, Bactoscilla mobilis nom.prov. has so far been found, and this only a few times and not in great numbers. It was first observed in scum composed mainly of Myxophyceae from the outlet of the 'Clay Pond' near the Freshwater Biological Association laboratory at Wray Castle, Ambleside, later in the surface film of water over black mud from Flatford Mill Field Centre, and a third time in mixed material from a duck-pond near Colchester.
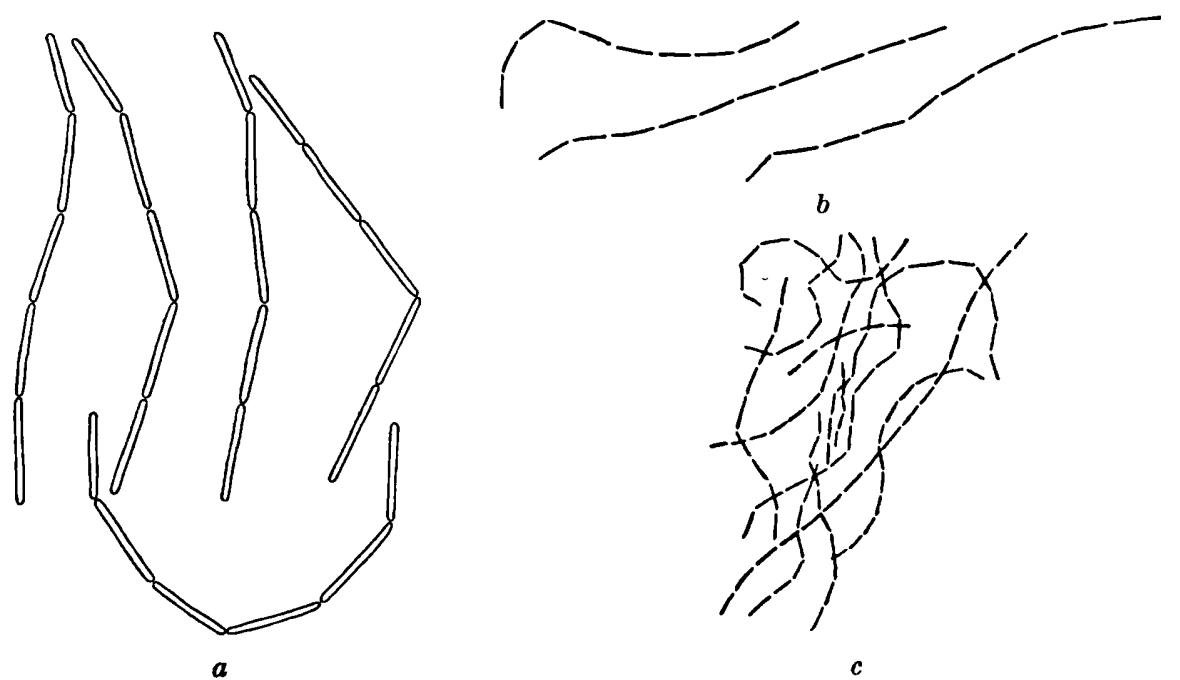

$b$

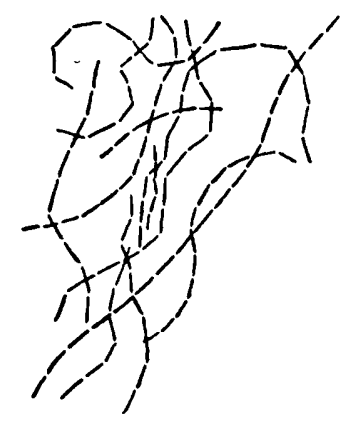

$c$

Fig. 16. Bactoscilla mobilis. a. Trichome of five rods, stages in quick change of position, and trichome of six rods, bending in joints; $\times 1250 . b$. Trichome of ten rods, stages in quick change; $\times 200$. c. Bundle of Trichomes; $\times 500$.

The cells of this organism are slender and rod-shaped, $0 \cdot 4 \mu$. wide, forming chains with gaps between the component rods (Fig. 16a). By its gliding movement the species appears to be related to the other Vitreoscillaceae, but owing to its minuteness its details could not be resolved even with a $\times 120$ Zeiss apochromatic oil immersion objective, $\times 8$ compensating eyepiece and optimum illumination, or with dark-ground illumination. The gliding movement of the trichomes is similar to that of other Vitreoscillaceae. Only when they are fastened with one end, and the other one bends and twists, does the peculiarity of the movement reveal itself, its most unusual feature being the rigidity of the individual rods, while bending takes place in the joints, the exact nature of which is not clear (Fig. 16b,c). These hinge-like movements remind one of the joints of an arm, but the whole trichome curves in various directions at short intervals.

One may wonder whether other filamentous gliding organisms behave fundamentally in the same way without this being observable because the cells are too short for their rigidity to be perceived. In Vitreoscilla moniliformis, the largest of the genus, trichomes composed of a few cells showed 
something of the kind, i.e. considerable bending of the whole chain without alteration in the shape of the cells. The generally accepted explanation of myxophycean locomotion by contraction and expansion of the cells cannot therefore be applied to the Vitreoscillaceae. In the Myxobacteria, on the other hand, the movement and appearance of which is so similar (Pringsheim, 1949, p. 86), a marked flexibility of the cells is readily observed. The Wray Castle form seems to have been larger though otherwise very similar. The material was scarce, and my notes do not suffice to establish the relationship. It was also not possible to decide whether the bending was passive like that of the other filamentous gliding organisms (cf. p. 133) or active and concentrated in the joints as the appearance suggested.

FLEXOSCILLA nom.prov.

Of this genus only one species, $\boldsymbol{F}$. mucronata n.sp., has been observed. It was detected in January 1942 in a culture of decaying algae from Coldham Common, Cambridge. Four months after the material had been brought in and small quantities of sodium sulphide had repeatedly been added, a large number of the organisms had grown in the bottom deposit and on the glass near the surface of the water. It glides rapidly and is a flexible, possibly unicellular rod, about $1 \mu$. wide and 12-15 $\mu$. long. Its external membrane is less distinct than that of Spirillum present in the same preparation and is scarcely illuminated by dark ground illumination. Both ends are tapering but are not acute. While moving the rods are usually almost straight (Fig. 17).

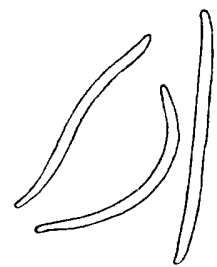

Fig. 17. Flexoscilla mucronata. Three specimens of various shapes which may all occur in the same individual by bending.

\section{DISCUSSION}

The search for colourless gliding organisms has led to the conclusion that there are many more species than have so far been identified. This is borne out first by the observation of these forms in various habitats; often only a small number of trichomes could be found, but these were sufficient to show that they were taxonomically distinct. Secondly, this view is supported by the fact that all the strains grown in pure culture represent different species so that further isolations should furnish a greater number of different species.

The Vitreoscillaceae will therefore probably prove to be as large a group as the Myxobacteria of which only a very restricted number has been studied. The Myxobacteria comprise members which decompose cellulose and chitin or are parasitic, but the majority live either on bacteria or on the products of bacterial metabolism. By contrast, none of the known Vitreoscillaceae seems to have special biochemical properties, but it would not be safe to say that this negative statement is final.

There is a decided similarity between the Vitreoscillaceae and the Myxobacteria which may indicate a real affinity. The two groups have the following characteristics in common: (1) lack of true cell walls composed of a substance 
chemically different from the cytoplasm, from which it separates in hypertonic solutions; (2) low refractivity due to high water-content and possibly to the absence of a rigid cell wall; (3) gliding movement, without observable cause and based on at least partial adherence to solid bodies or the water-air interface; $(4)$ the more-or-less pronounced trichome formation.

There are also distinct morphological differences between the Vitreoscillaceae and the Myxobacteria, indicating a higher organization in the latter: (1) the so-called microcysts which perhaps all species are able to produce; (2) the fruiting bodies of the higher Myxobacteria. Most of the Vitreoscillaceae are also more pronouncedly filamentous, some of them even forming threads of great length while the majority of the Myxobacteria produce only elongate rods, and the trichomes formed by a few of them are only short.

In respect of filament formation some of the Vitreoscillaceae resemble the Beggiatoaceae which also glide in a similar way. Beggiatoa alba, the best-known species, is different from most species of the Vitreoscillaceae, though not from Vitreoscilla filiformis, in the unrestricted length of the smooth, cylindrical trichomes while most species of Vitreoscilla have more or less rounded cells and shorter trichomes. This phenomenon has, however, also been observed in Beggiatoa mirabilis (cf. Benecke, 1912, p. 205), so that there is no fundamental difference in this respect. The similarity between trichomes of Vitreoscilla and those of Beggiatoa when sulphur-free, may be so great that one might easily be mistaken for the other. In fact, Beggiatoa alba can be isolated and grown in pure culture in much the same way as Vitreoscilla (Cataldi, 1940; personal observations).

The taxonomic position of the Vitreoscillaceae seems to be intermediate between the Myxobacteria and the Beggiatoaceae, which are most probably apochlorotic descendants of Myxophyceae (Pringsheim, 1949, p. 63). Before we know more of their cell organization the true relationship between the three groups cannot be established. Cytological investigations, in which Mrs Klieneberger-Nobel (Lister Institute, London) and Dr C. F. Robinow (then at the Strangeways Laboratory, Cambridge) very kindly assisted me, proved to be as difficult as in the case of Myxophyceae. One of the reasons is the inconstancy of the morphological features of the Vitreoscillaceae. It is nevertheless certain that Feulgen-positive nuclear structures are present, two in each cell but sometimes more in inflated forms (Pl. 3, figs. 5-7).

A constant feature of Vitreoscillaceae as of Beggiatoaceae and Myxobacteria is the mucilage production which appears to be connected with the gliding movement, since in all organisms exhibiting locomotion of this kind the cells are embedded in a slimy mass. They also leave tracks which can clearly be seen on agar. Otherwise the mechanism of the movement is as mysterious as that of other gliding organisms.

The ease with which these organisms can be kept and grown makes them valuable objects of research into cell physiology and nutrition. In order to facilitate such work cultures of Vitreoscilla, Beggiatoa and Myxobacteria are kept for general use in the Culture Collection of the Botany School, Cambridge. 


\section{DIAGNOSES}

Vitreoscillaceae Pringsheim nov.fam., colourless, filamentous, gliding micro-organisms, differing from Myxophyceae in lacking assimilatory pigments, and from Myxobacteria by a more pronounced trichome formation and the absence of microcysts. Type genus Vitreoscilla Pringsheim.

Vitreoscilla Pringsheim, nov.gen. Trichomes clearly subdivided into cells. Reproduction by hormogonium-like trichome fragments. The sites of fragmentation are usually indicated beforehand by contractions between the cells.

(1) V. beggiatoides. Trichomes 1-2 $\mu$. wide, may become very long. They are subdivided by shallow constrictions. Cells elongate, cylindrical, varying much in length. Growth on agar composed of long trichomes forming curls and projections. Type-strain isolated in June 1941 from cow dung. The same species isolated again from:

(2) $V$. catenula. Trichomes 1.2-2 $\mu$. wide, often moniliform, never very long, fragmenting in a variety of ways. Grows on agar in spirals and whorls. Type strain isolated in November 1945 from cow dung. The same species was found in an infusion of plant material from:

(3) $V$. filiformis. Trichomes $1 \cdot 2 \mu$. wide, very long and tough, cylindrical. Cells short, cylindrical. On agar circular spirals and loose loops. Isolated in February 1946 from soil, but also occurring in water.

(4) $V$. moniliformis. Trichomes $1 \cdot 8-2 \cdot 5 \mu$., rarely up to $3 \mu$. in diameter, usually about $25-40 \mu$. long, but sometimes up to $150 \mu$. Cells vary from spherical to rod-shaped, usually rounded so that trichomes are moniliform. On agar rich in nutrients, diffuse growth spreading in zones. When less well nourished filamentous loops and projections. Isolated from cow dung in June 1947.

(5) V. paludosa. Trichomes $1 \cdot 8-2 \mu$ wide, often very long, up to $300 \mu$,, sometimes even more, composed of rod-shaped cells $30-70 \mu$. in length. Colonies on agar often showing concentric structures with the edge growing out into projections and curls. Isolated in November 1947 from water with decaying algae.

(6) V. stercoraria. Trichomes $1 \cdot 2-1 \cdot 5 \mu$. wide, sometimes involuted to $1 \cdot 8 \mu$. of varying length, up to $100 \mu$. They are composed of cells, the length of which is from about the same as the diameter to $12 \mu$. and more. Growth on nutrient agar luxuriant. Colonies spiral, characteristically connected by a fine network of trichomes, especially on a less rich agar medium. Isolated from cow dung in May 1946.

Microscilla nov.gen. Trichomes narrow without perceptible septation. Gliding movements active. Reproduction by division into relatively long daughter trichomes. Type species $M$. marina.

M. marina. Trichomes $0 \cdot 5-0 \cdot 6 \mu$. wide, up to $100 \mu$. long, cylindrical. Constrictions few, occurring only before division. On agar, translucent colonies composed of loops and whorls. Type strain isolated in December 1947 from marine algae on chalk in the tidal zone at Brighton, Sussex, England.

Bactoscilla nov.gen. Trichomes narrow, composed of rod-shaped sections 
which are relatively rigid and held together by an invisible, pliable connexion. Type species $B$. mobilis.

Flexoscilla nov. gen. Trichomes short, possibly unicellular, tapering at both ends. Type species $F$. mucronata.

\section{REFERENCES}

BaAs-Becking, L. G. M. (1925). Studies on the sulphur bacteria. Ann. Bot., Lond., 39, 613.

BenECKe, W. (1912). Bau und Leben der Bakterien. Leipzig und Berlin : B. G. 'Teubner. Bergey's Manual of Determinative Bacteriology (1948), 6th ed. Breed, R. S., Murray, E. G. D. \& Hitchens, A. P. Baltimore: Williams and Wilkins.

Brunel, J. (1949). Achroonema Spiroideum Skuja 1948, of the Trichobacteriales, discovered simultaneously in Sweden and in Canada. Contr. Inst. Univ. Montréal, 64, 21.

Cataldi, M. S. (1940). Aislamiento de Beggiatoa alba en cultivo puro. Rev. Inst. Bact., B. Aires, 9, 293.

Cataldi, M. S. (1941). Aislamiento en culturo puro de Cianoficeas y algas monocelulares. Darwiniana, B. Aires, 5, 228.

Cons, F. (1870-1). Über den Brunnenfaden (Crenothrix polyspora), nebst Bemerkungen über die mikroskopische Analyse des Brunnenwassers. Beitr. Biol. Pfl. 1, 108.

Correns, C. (1897). Ueber die Membran und die Bewegung der Oscillarien. Ber. dtsch. bot. Ges. 15, 139.

Dobell, C. (1908). Notes on some parasitic protists. Quart. J. micr. Sci. 52, 121.

DoBell, C. (1912). Researches on the Spirochaetes and related organisms. Arch. Protistenk. 26, 117.

Engelmann, Th. W. (1879). Ueber die Bewegungen der Oscillarien und Diatomeen. Bot. Ztg. 37, 49.

Fechner, R. (1915). Die Chemotaxis der Oscillarien und ihre Bewegungserscheinungen überhaupt. Z. Bot. 7, 289.

GarnJoBst, L. (1945). Cytophaga columnaris (Davis) in pure culture: a myxobacterium pathogenic to fish. J. Bact. 49, 113.

Hansgirg, A. (1887). Physiologische und algologische Studien. Prague.

Kolkwitz, R. (1897). Über die Krümmungen und den Membranbau einiger Spaltalgen. Ber. dtsch. bot. Ges. 15, 460.

Kolkwitz, R. (1909). Schizomycetes, Spaltpilze (Bacteria). Kryptogamenflora d. Mark Brandenburg, 5. Leipzig: Bornträger.

Lauterborn, R. (1915) (1914-17). Die sapropelische Lebewelt. Ein Beitrag zur Biologie des Faulschlammes natürlicher Gewässer. Verh. naturh.-med. Ver. Heidelberg, N.F. 13, 395.

NiEL, C. B. vaN (1931). On the morphology and physiology of the purple and green sulphur bacteria. Arch. Mikrobiol. 3, 1.

Nigrelli, R. \& Hutner, S. H. (1945). The presence of a Myxobacterium Chondrococcus columnaris (Davis) Ordal \& Rucker (1944), on Fundulus heteroclitus (Linn.). Zoologica, N.Y. 30, 101.

Nikltsschek, A. (1934). Das Problem der Oscillatorien-Bewegung I. Die Bewegungserscheinungen der Oscillatorien. Beih. Bot. Zbl. A, 52, 205.

Peshroff, M. A. (1940). Phylogenesis of new microbes, Caryophanon latum and Caryophanon tenue, organisms which are intermediate between blue-green algae and the bacteria (Summary in English). J. gen. Biol., U.S.S.R. 1, 598.

Pringsheim, E. G. (1949). The relationship between Bacteria and Myxophyceae. Bact. Rev. 13, 47.

Pringsheim, E. G. (1950). The bacterial genus Lineola. J. gen. Microbiol. 4, 158. 
Journal of General Microbiology, Vol. 5, No. 1

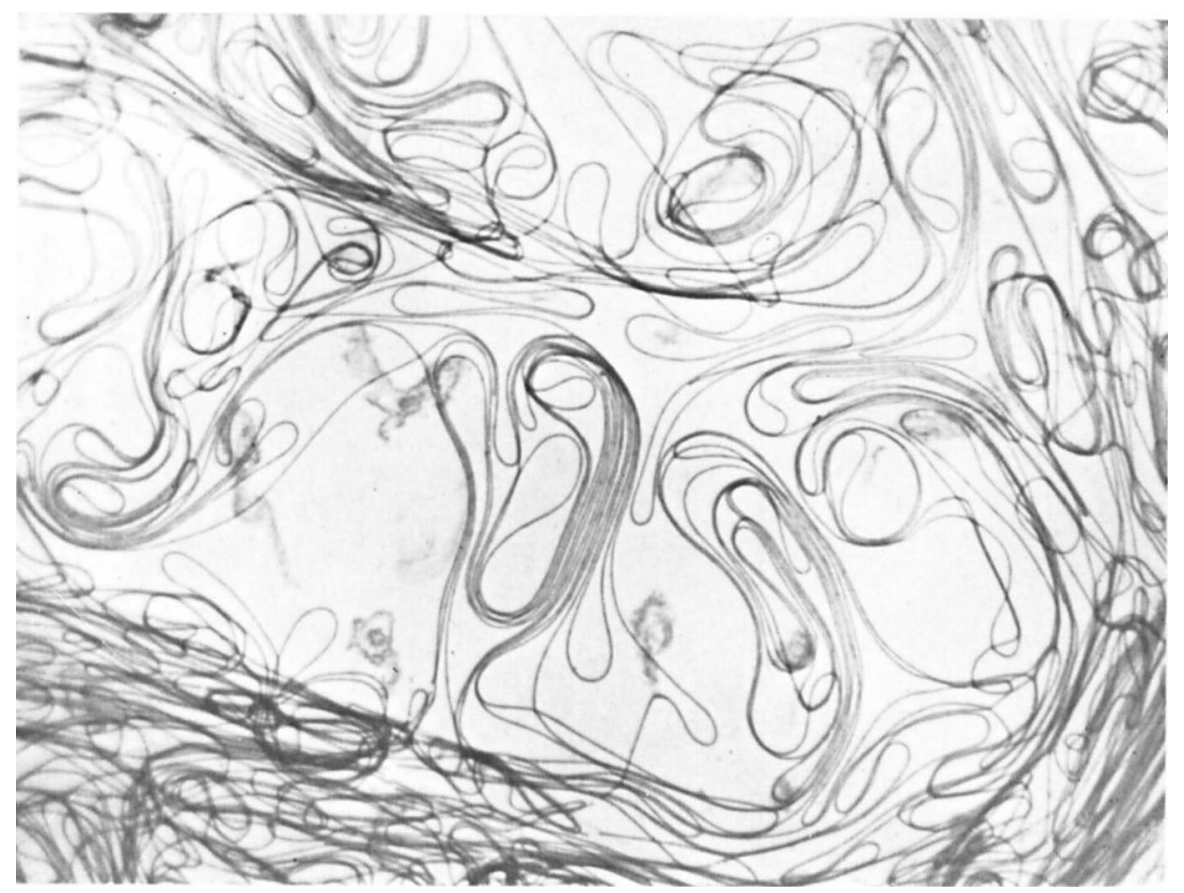

Fig. 1

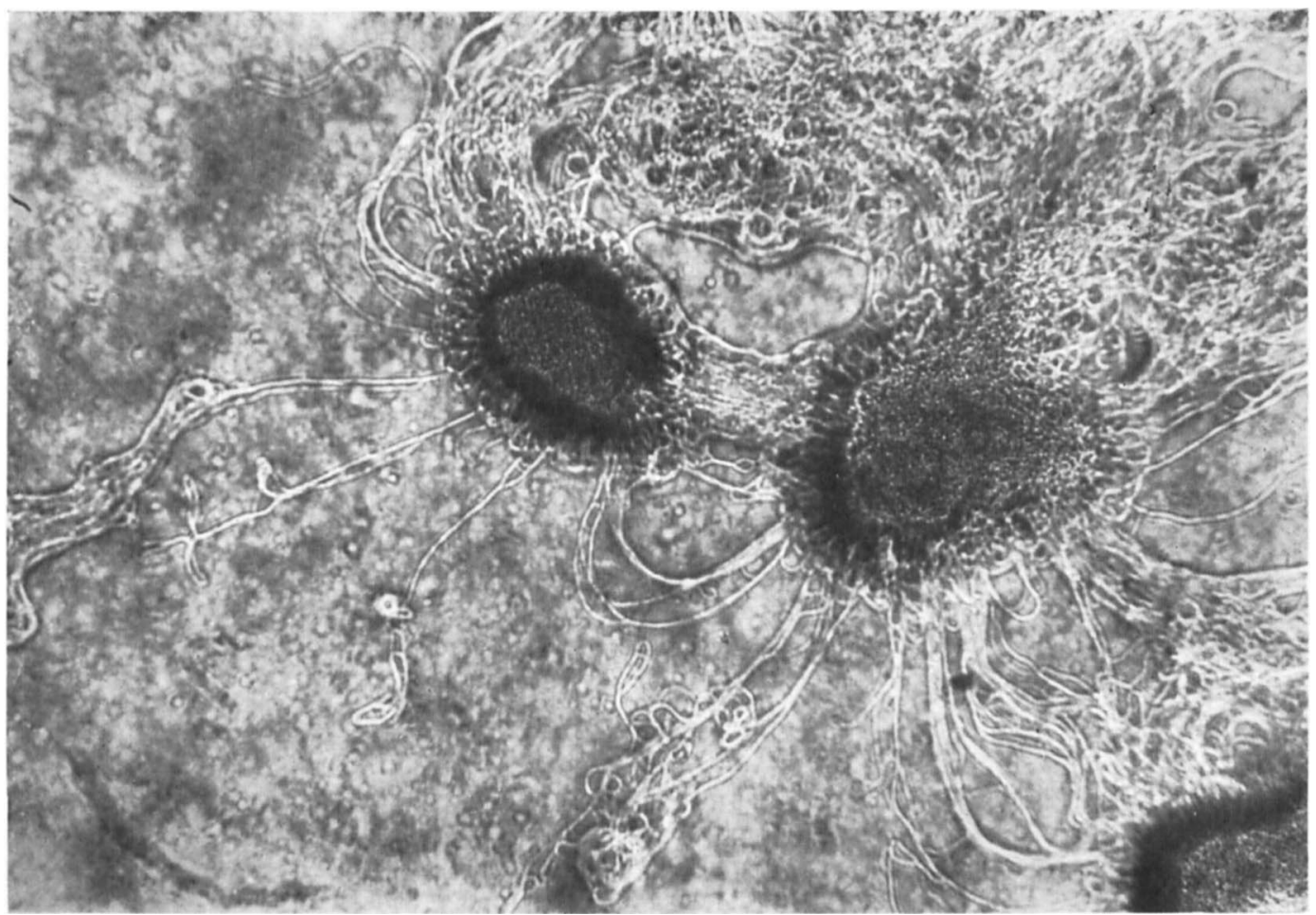

Fig. 2 
Journal of General Microbiology, Vol. 5, No. 1

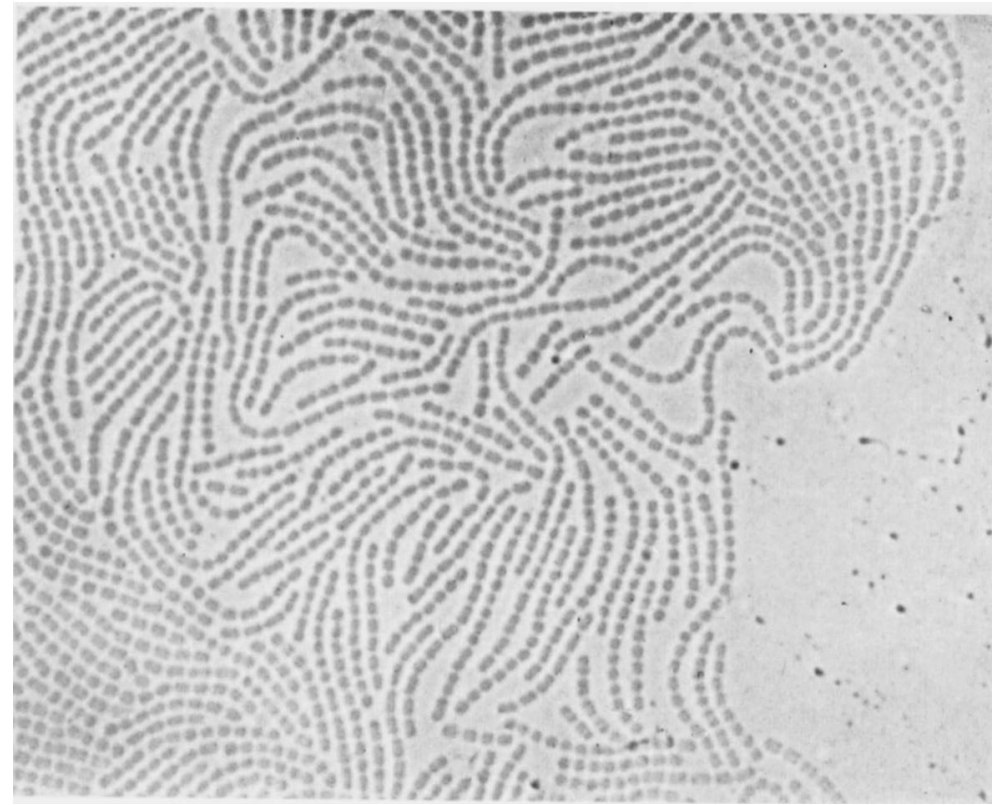

Fig. 3

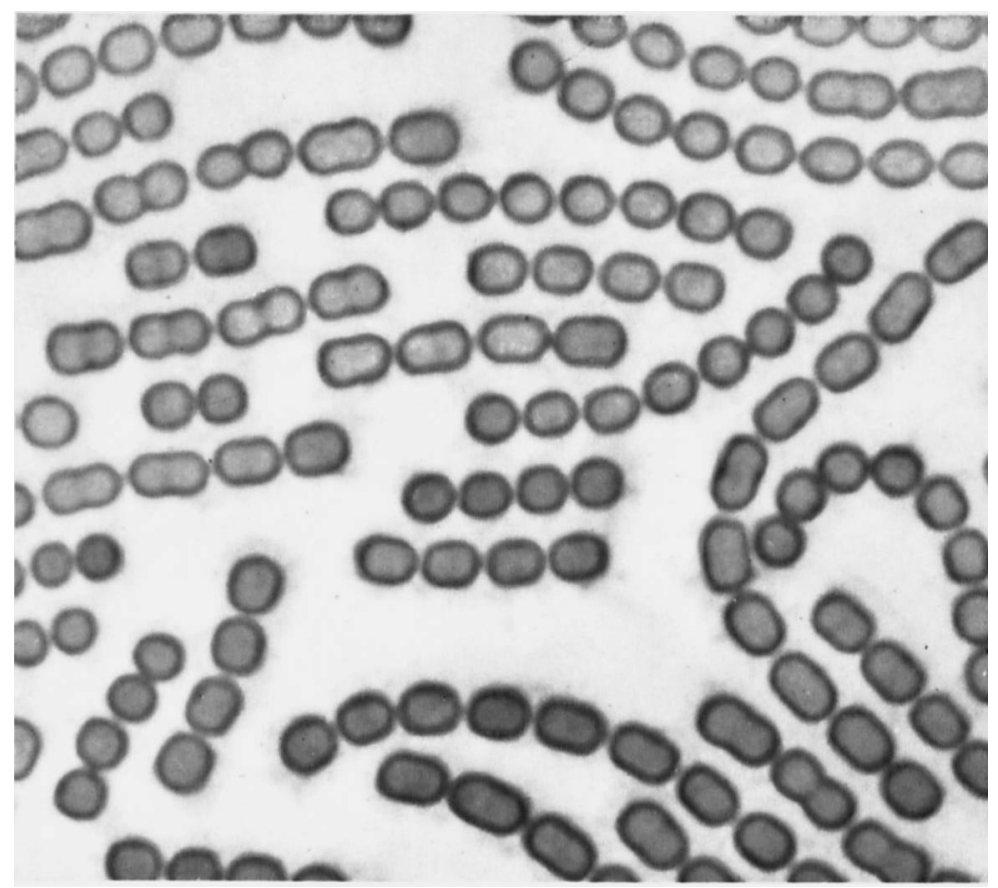

Fig. 4

E. G. Pringsheim-The Vitreoscillaceat. Plate 2 
Journal of General Microbiology, Vol. 5, No. 1

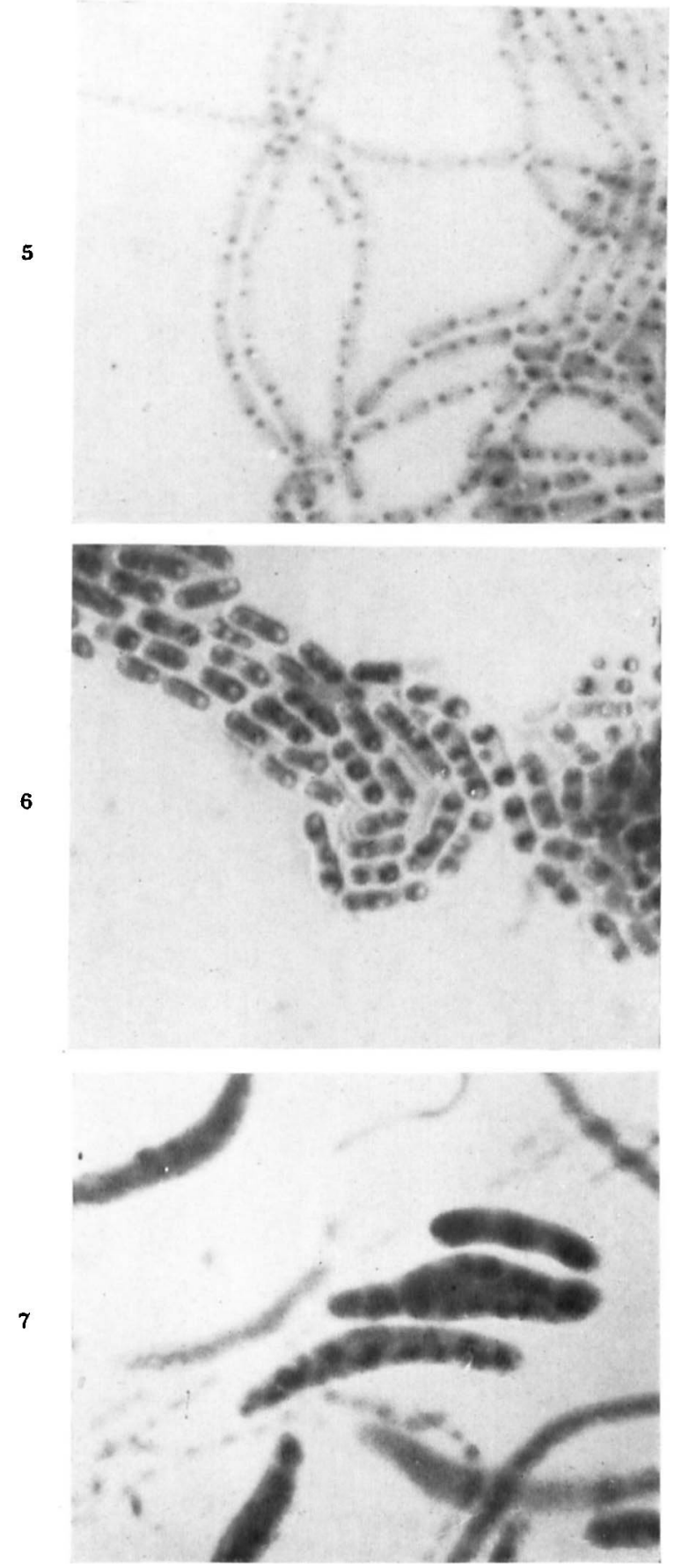

Figs. 5-7.

E. G. Pringsheim-The Vitreoscillaceae. Plate 3 

Pringsheim, E. G. \& Robinow, C. F. (1947). Observations on two very large Bacteria, Caryophanon latum Peshkoff and Lineola longa (nomen provisorium). J. gen. Microbiol. 1, 267.

Schmid, G. (1918). Zur Kenntnis der Oscillarienbewegung. Flora, Jena, 111/12, 327.

Schмid, G. (1919). Ein Hilfsmittel zum Unterscheiden verschiedener Oscillatoriaund Phormidium- Arten. Ber. dtsch. bot. Ges. 37, 473.

SkujA, H. (1948). Taxonomie des Phytoplanktons einiger Seen in Uppland, Schweden. Symb. bot. upsaliens. 9, 3.

Soriano, S. (1947). The Flexibacteriales and their systematic position. Antonie van Leeuwenhoek, J. Microbiol. \& Serol. 12, 215.

Tieghem, P. van (1880). Observations sur les Bactériacés vertes, sur les Phycochromacés blanches et sur les affinités de ces deux familles. Bull. Soc. bot. Fr. 27,174 .

UlLRICH, H. (1926). Ueber die Bewegungen von Beggiatoa mirabilis und Oscillatoria jenensis I. Planta, 2, 295.

UllRICH, H. (1929). Ueber die Bewegungen der Beggiatoaceen und Oscillatoriaceen II. Planta, 9, 144.

Winogradsky, S. (1888). Beiträge zur Morphologie und Physiologie der Bakterien I. Schrefelbakterien. Leipzig: W. Englemann.

ZoBell, C. E. (1946). Marine Microbiology, Waltham, Mass., U.S.A.: Chronica Botanica Company.

\section{EXPLANATION OF PLATES}

Plate 1. Vitreoscilla filiformis

Fig. 1. Part of large colony on nutrient agar, Bouin Giemsa; $\times 420$ (prep. and phot. Robinow).

Fig. 2. Trichomes growing out of soil particles on agar plate (phot. Rothamsted).

Plate 2. Vitreoscilla moniliformis

Fig. 3. Edge of living, 3-day-old colony; $\times 720$ (phot. Robinow).

Fig. 4. Part of the same colony, Bouin tannic acid + crystal violet; $\times 3000$ (prep. and phot. Robinow).

Plate 3. Vitreoscilla stercoraria

Fig. 5. Meat infusion agar, $18 \mathrm{hr}$., $37^{\circ}$, osmic acid thin Giemsa.

Fig. 6. Yeast extract agar, $24 \mathrm{hr}$. room temperature, osmic acid $\mathrm{HCl}$ Giemsa.

Fig. 7. Yeast extract agar, 3 days room temperature, osmic acid thin Giemsa (prep. and phot. Klieneberger-Nobel). 